\title{
Pursuing the Mechanisms Underlying Alcohol-Induced Changes in the Ghrelin System: New Insights from Preclinical and Clinical Investigations
}

Mehdi Farokhnia ${ }^{1,2,3^{*}}$, Sara L. Deschaine ${ }^{1 *}$, Adriana Gregory-Flores ${ }^{1,4}$, Lia J. Zallar ${ }^{1,4}$, Zhi-Bing You ${ }^{5}$, Hui Sun $^{6}$, Deon M. Harvey ${ }^{7}$, Renata C.N. Marchette ${ }^{2,4}$, Brendan J. Tunstall ${ }^{4}$, Bharath K. Mani ${ }^{8}$, Jacob E. Moose $^{9,10}$, Mary R. Lee ${ }^{1}$, Eliot Gardner ${ }^{5}$, Fatemeh Akhlaghi ${ }^{11}$, Marisa Roberto ${ }^{12}$, James L. Hougland ${ }^{9,10,13}$, Jeffrey M. Zigman ${ }^{8,14,15}$, George F. Koob ${ }^{4}$, Leandro F. Vendruscolo ${ }^{4}$, Lorenzo Leggio ${ }^{1,2,16,17,18,19 \# ~}$

1. Clinical Psychoneuroendocrinology and Neuropsychopharmacology Section, National Institute on Drug Abuse and National Institute on Alcohol Abuse and Alcoholism, National Institutes of Health, Baltimore and Bethesda, MD, USA

2. Center on Compulsive Behaviors, National Institutes of Health, Bethesda, MD, USA

3. Johns Hopkins Bloomberg School of Public Health, Johns Hopkins University, Baltimore, MD, USA

4. Neurobiology of Addiction Section, Intramural Research Program, National Institute on Drug Abuse, National Institutes of Health, Baltimore, MD, USA

5. Neuropsychopharmacology Section, Molecular Targets and Medications Discovery Branch, National Institute on Drug Abuse, National Institutes of Health, Baltimore, MD, USA

6. Clinical Core Laboratory, Office of the Clinical Director, National Institute on Alcohol Abuse and Alcoholism, National Institutes of Health, Bethesda, MD, USA

7. Office of the Scientific Director, National Institute on Drug Abuse, National Institutes of Health, Baltimore, MD, USA

8. Center for Hypothalamic Research, Department of Internal Medicine, UT Southwestern Medical Center, Dallas, TX, USA

9. Syracuse Biomaterials Institute, Syracuse University, Syracuse, NY, USA

10. Department of Chemistry, Syracuse University, Syracuse, NY, USA 
11. Clinical Pharmacokinetics Research Laboratory, Department of Biomedical and Pharmaceutical Sciences, University of Rhode Island Kingston, RI, USA

12. Department of Neuroscience, The Scripps Research Institute, La Jolla, CA, USA

13. BioInspired Syracuse, Syracuse University, Syracuse, NY USA

14. Division of Endocrinology, Department of Internal Medicine, UT Southwestern Medical Center, Dallas, TX, USA

15. Department of Psychiatry, UT Southwestern Medical Center, Dallas, TX, USA

16. Medication Development Program, National Institute on Drug Abuse Intramural Research Program, National Institutes of Health, Baltimore, MD, USA

17. Center for Alcohol and Addiction Studies, Department of Behavioral and Social Sciences, School of Public Health, Brown University, Providence, RI, USA

18. Division of Addiction Medicine, Department of Medicine, School of Medicine, Johns Hopkins University, Baltimore, MD USA

19. Department of Neuroscience, Georgetown University Medical Center, Washington DC, USA

*MF and SD contributed equally to this work.

${ }^{\#}$ Corresponding Author: Lorenzo Leggio, M.D., Ph.D.

NIDA and NIAAA, National Institutes of Health

251 Bayview Boulevard, Biomedical Research Center, Room 01A844, Baltimore, MD 21224

Email: Lorenzo.leggio@nih.gov

Short Title: Ghrelin and Alcohol

Keywords: Acyl-ghrelin, des-acyl-ghrelin, total ghrelin, alcohol, GOAT 


\section{Abstract:}

Ghrelin is a gastric-derived peptide hormone with demonstrated impact on alcohol intake and craving, but the reverse side of this bidirectional link, i.e., the effects of alcohol on the ghrelin system, remains to be fully established. To characterize the downstream effects of alcohol on the ghrelin system, we examined the following: (1) plasma ghrelin levels across four human laboratory alcohol administration experiments with non-treatment seeking, heavy-drinking participants, (2) expression of ghrelin, ghrelin receptor, and ghrelin-O-acyltransferase (GOAT) genes (GHRL, GHSR, and MBOAT4, respectively) in human post-mortem brain tissue from individuals with alcohol use disorder (AUD) vs. controls, (3) plasma ghrelin levels in Ghsr knockout and wild-type rats following intraperitoneal (i.p.) ethanol administration, (4) effect of ethanol on ghrelin secretion from gastric mucosa cells ex vivo and GOAT enzymatic activity in vitro, and (5) plasma ghrelin levels in rats following i.p. ethanol administration vs. an iso-caloric sucrose solution. Peripheral acyl- and total ghrelin levels significantly decreased following acute ethanol administration in humans. No difference in GHRL, GHSR, and MBOAT4 mRNA expression in the brain was observed between AUD vs. control post-mortem samples. In rats, acyl-ghrelin levels significantly decreased following i.p. ethanol administration in both genotype groups (Ghsr knockout and wild-type), while des-acyl-ghrelin was not affected by ethanol. No effect of ethanol was observed ex vivo on ghrelin secretion from gastric mucosa cells or in vitro on GOAT acylation activity. Lastly, we observed different effects of i.p. ethanol and sucrose solution on acyl- and des-acyl-ghrelin in rats despite administering amounts with equivalent caloric value. Ethanol acutely decreases peripheral ghrelin concentrations in humans and rats, and our findings suggest that this effect does not occur through interaction with ghrelin-secreting gastric mucosal cells, the ghrelin receptor, or the GOAT enzyme. Moreover, this effect does not appear to be proportional to caloric load. Our findings, therefore, suggest that ethanol does not suppress circulating ghrelin through direct interaction with the ghrelin system, or in proportion to the caloric value of alcohol, and may differentially affect ghrelin acylation and ghrelin peptide secretion. 
bioRxiv preprint doi: https://doi.org/10.1101/2020.07.30.228494; this version posted July 31, 2020. The copyright holder for this preprint (which was not certified by peer review) is the author/funder. This article is a US Government work. It is not subject to copyright under 17 USC 105 and is also made available for use under a CCO license. 


\section{Introduction:}

Alcohol use disorder (AUD) is a chronic relapsing disease characterized by excessive consumption of alcohol to an extent that causes significant harm to the affected individual's health and overall quality of life. According to the 2018 National Survey on Drug Use and Health, 5.8\% of individuals aged 18 and older in the United States had AUD in the past year, and an estimated 88,000 annual deaths are alcohol-related [1, 2]. Still, only three Food and Drug Administration (FDA)-approved medications are available for treatment of AUD, highlighting a significant need to develop novel pharmacotherapies for AUD. One such therapeutic strategy is based on the notion that harmful alcohol consumption can be alleviated by pharmacologically manipulating endocrine pathways that control both homeostatic and hedonic feeding, as well as stress-related pathways and reward processing [3-5]. Indeed, the orexigenic peptide ghrelin is one hormone that has been shown to play a role in alcohol-related behavior across numerous studies [6-8].

Ghrelin is a 28 amino acid hormone secreted primarily from P/D1 cells (X/A-like cells in rodents) located in the oxyntic glands of the fundus portion of the stomach. Encoded by the ghrelin gene $(G H R L)$, ghrelin is post-translationally formed by cleavage of the 117 amino acid preproghrelin into proghrelin, which can then be acylated at the serine-3 residue by the membrane-bound enzyme, ghrelin Oacyltransferase (GOAT) [9-12]. Acylated proghrelin is then cleaved to form acyl-ghrelin - the endogenous ligand of the growth hormone secretagogue receptor 1a (GHSR1a). Acylation of ghrelin is essential for binding to GHSR1a, both centrally and peripherally, and mediates orexigenic effects $[9,13$, 14]. Much research over the past decade demonstrates that the ghrelin system has a complex biology, due to several factors: (1) circulating acyl-ghrelin in can be de-acylated by plasma esterases to des-acylghrelin [15]; (2) GOAT can acylate ghrelin in target tissues, both in the central nervous system and the periphery [16-18]; (3) plasma anti-ghrelin immunoglobulin Gs (IgGs) may bind and protect ghrelin from degradation in circulation [19]; (4) des-acyl-ghrelin may have effects seemingly opposite to acyl-ghrelin through GHSR1a-independent mechanisms [20]; and (5) GHSR1a has high constitutive, ligand- 
independent activity [21, 22]. Moreover, an endogenous antagonist/inverse agonist for GHSR1a, known as liver-expressed antimicrobial peptide-2 (LEAP-2), was recently identified [23-25]. These different components of the ghrelin system help regulate and balance acyl-ghrelin's important effects on energy homeostasis to ensure survival of the organism [26].

Central signaling of the gastric-derived acyl-ghrelin occurs through activation of GHSR1a expressed on vagal afferent neurons in the stomach, as well as by acyl-ghrelin crossing the blood-brain barrier and binding to GHSR1a in the brain [27]. Acyl-ghrelin's central orexigenic signaling occurs directly through GHSR1a expressed on hypothalamic neuropeptide Y and agouti-related, peptideexpressing neurons in the arcuate nucleus, and indirectly through activation of the lateral hypothalamus, hippocampus, amygdala, ventral tegmental area (VTA), and other regions [27]. These brain regions communicate with origins and terminal regions of the mesolimbic dopamine system, which affects motivational components of behaviors, including hedonic feeding and drug and alcohol seeking. Indeed, administration of acyl-ghrelin into the brain's reward circuitry increases extracellular dopamine via GHSR1a, located in the mesolimbic pathway [28-35], and stimulates food intake [36, 37]. By communicating with these regions, the ghrelin system can regulate homeostatic and hedonic drives governing food-seeking behavior that seem to similarly affect alcohol-seeking behavior. In rodents, central or systemic ghrelin administration increases alcohol intake, whereas antagonism of GHSR1a and knockout of Ghrl or Ghsr decreases alcohol preference and consumption and blunts both conditioned place preference and dopamine release in the nucleus accumbens (NAc) induced by alcohol [38-43]. Moreover, higher peripheral ghrelin concentrations are positively correlated with alcohol craving and risk of relapse in humans $[40,44-48]$, and exogenous ghrelin administration increases cue-induced craving [45] and intravenous self-administration of alcohol in heavy-drinking individuals with alcohol dependence [49]. Collectively, these studies demonstrate a clear relationship between ghrelin and alcoholrelated behavior, wherein ghrelin appears to potentiate alcohol seeking and consumption, and partly regulate its reinforcing effects. 
To obtain a better understanding of the crosstalk between ghrelin and alcohol, further research into how alcohol affects the ghrelin system is critically needed. To date, only a few studies have examined the effect of alcohol on peripheral ghrelin concentration. In rodents, alcohol acutely decreased both acyl-ghrelin and total-ghrelin concentration in plasma $[50,51]$, and in humans, acute administration of alcohol decreased plasma ghrelin concentrations [52-57]. Amongst individuals with alcohol dependence, abstainers had higher peripheral ghrelin concentrations compared to current drinkers [44, 47, 48, 58-63]. Ghrelin concentrations were significantly lower in individuals with alcohol dependence compared to matched, non-dependent controls [44]. However, mean daily alcohol consumption over the past 12 months was positively correlated with plasma ghrelin concentrations among individuals without an AUD diagnosis [64]. Collectively, these studies suggest that acute and chronic exposure to alcohol differentially affect the ghrelin system, with effects from chronic alcohol use likely reflecting compensatory mechanisms dependent on the extent and duration of an individual's alcohol use. Although the literature to date demonstrates an interplay between alcohol and ghrelin, it is unclear how these effects are occurring - whether through direct action on ghrelin-producing cells, modification of GOAT activity, and/or through other mechanism(s). The objective of the present body of work was to further probe the effect of alcohol on the ghrelin system and its underlying mechanisms through experiments performed in humans and rodents, ex vivo experiments, and in vitro experiments.

\section{Results:}

\subsection{Plasma Ghrelin Levels are Reduced after Alcohol Administration in Humans}

We examined plasma ghrelin levels following intravenous or oral alcohol administration during four different human laboratory experiments in non-treatment-seeking, heavy-drinking individuals (Table S1, Figure S1-4). Each experiment was originally conducted as part of a parent study designed to evaluate the effects of a pharmacological intervention on alcohol-related outcomes $[49,65,66]$. Here, we performed secondary analyses for each experiment using data from the placebo groups of these parent 
studies. Each experiment had a unique design, with alcohol being administered orally or intravenously (IV) in both self-administration and fixed-dose schedules (four experiments in total) (see Figure 1 and Table S2 for details). We evaluated changes in acyl-ghrelin and total-ghrelin during each alcohol administration experiment, which allowed us to compare different routes of alcohol administration.

Overall, alcohol administration led to a reduction in ghrelin levels, regardless of the route of ethanol administration, within a time period ranging from 45 - $165 \mathrm{~min}$. Using linear mixed effects modeling, we found that acyl-ghrelin $[\mathrm{F}(3,27.5)=6.6, \mathrm{p}=0.002]$ and total ghrelin $[\mathrm{F}(3,37.7)=4.5, \mathrm{p}=$ 0.009] were significantly reduced during the variable dose oral alcohol administration session (Figure 2A). Moreover, there was a significant reduction in acyl-ghrelin $[F(5,53.8)=10.5, p<0.001]$ and total ghrelin $[\mathrm{F}(5,52)=13.6, \mathrm{p}<0.001]$ during the fixed oral alcohol administration session (Figure 2B). Analysis of peripheral ghrelin during the variable dose IV alcohol administration session also revealed a significant reduction in both acyl-ghrelin $[\mathrm{F}(4,37.7)=7.5, \mathrm{p}<0.001]$, and total ghrelin [Covariate: Gender, $\mathrm{F}(4,38.7)=5.6, \mathrm{p}=0.001]$ (Figure 2C). Lastly, we observed a reduction in acyl-ghrelin $[\mathrm{F}$ $(4,19)=2.0, \mathrm{p}=0.134)$ and total-ghrelin $[\mathrm{F}(4,17.1)=2.7, \mathrm{p}=0.067]$ during the fixed IV alcohol administration session, but this change did not reach statistical significance (Figure 2D). Pairwise comparisons corrected for multiple testing were conducted between all timepoints for experiments where significant overall effects were found and are presented in Figure 2.

\subsection{GHSR, GHRL, and MBOAT4 Expression Levels in Select Brain Regions Are Not Significantly}

\section{Altered by Chronic Ethanol Consumption}

We further examined the effect of alcohol on the ghrelin system by determining whether severe alcohol use disorder (AUD), as indexed by DSM-5 AUD, affected central expression levels of GHRL, GHSR, or the GOAT enzyme gene, MBOAT4. Fold changes of GHSR mRNA, GHRL mRNA, and MBOAT4 mRNA expression levels in postmortem brain tissue [regions that have been shown to be affected by long term alcohol use (hippocampus, VTA, amygdala, prefrontal cortex (PFC) - superior frontal Brodmann area 12 and 13, and NAc] were compared between AUD individuals $(\mathrm{N}=11)$ and 
controls $(\mathrm{N}=15-16)$ (Table 1). Baseline characteristics of the sample are provided in Table S3. Using linear mixed effects modeling, we found no significant effect of group (AUD vs. control) on GHRL or GHSR expression in any of these brain regions tested (Figure 3, Table 1).

\subsection{Acyl-Ghrelin Levels are Reduced by Ethanol in Rats, Independent of Ghrelin Receptor Knockout (KO)}

We next examined whether a change in ghrelin levels as a result of ethanol administration, as observed in our human laboratory experiments, could be replicated in rodents, and whether this effect would depend on the presence of the ghrelin receptor. We evaluated changes in plasma acyl- and desacyl-ghrelin levels $15 \mathrm{~min}$ following an intraperitoneal (i.p.) injection of ethanol $(1.5 \mathrm{~g} / \mathrm{kg}$ ) or saline in wild-type (WT) and ghrelin receptor knockout (Ghsr KO) male rats. Using two-way ANOVA, we observed a significant main effect of treatment (ethanol vs. saline) on acyl-ghrelin levels $[\mathrm{F}(1,29)=6.212$, $p=0.019$, where levels of acyl-ghrelin in ethanol-treated rats were reduced compared with saline-treated rats. There was no main effect of genotype (WT vs. KO) $[\mathrm{F}(1,29)=0.2309, \mathrm{p}=0.63]$ or treatment $\times$ genotype interaction $[\mathrm{F}(1,29)=0.01, \mathrm{p}=0.92]$ (Figure 4A). Moreover, there was no effect of treatment $[F(1,29)=0.013, p=0.91]$, genotype $[F(1,29)=0.3245, p=0.57]$, or treatment $x$ genotype interaction $[\mathrm{F}(1,29)=0.003, \mathrm{p}=0.95]$ on plasma des-acyl-ghrelin levels (Figure 4B).

\subsection{Ghrelin Secretion from Gastric Mucosa Cells is Not Altered by Ethanol}

Given that we found ethanol reduced acyl-ghrelin secretion in both human and animal experiments, we hypothesized that ethanol may have a direct effect on ghrelin release from the gastric mucosal cells. To test this hypothesis, we evaluated ghrelin release from gastric mucosal cells in the presence of different concentrations of ethanol. We cultured cells in both $5 \mathrm{mM}$ glucose environment and $0 \mathrm{mM}$ glucose environments. A $5 \mathrm{mM}$ glucose condition was used to study the effect of ethanol in settings simulating physiological blood glucose concentrations. A $0 \mathrm{mM}$ glucose condition was used to study the effect of ethanol without any interference of glucose as an energy source, and is known to be associated with higher ghrelin secretion as compared to $5 \mathrm{mM}$ glucose [67]. Because it has been shown to 
stimulate ghrelin secretion from primary cultures of gastric mucosal cells, norepinrephine $(10 \mu \mathrm{M})$ was used as a positive control for ghrelin secretion [68]. As observed previously [67], absence of glucose (0 $\mathrm{mM}$ vs. $5 \mathrm{mM}$ ) increased acyl-ghrelin secretion from primary cultrues of gastric mucosal cells. However, ethanol did not change acyl-ghrelin secretion at any of the concentrations tested (Figure 5A-C).

\subsection{Human GOAT (hGOAT) Acylation Activity Is Not Affected by Ethanol}

Having shown that ethanol does not affect ghrelin secretion in gastric mucosal cells and that the effects of ethanol on ghrelin levels are independent of the presence or absence of its receptor, we questioned whether ethanol may have direct effects on other components of the ghrelin system, for example, the GOAT enzyme. Therefore, we assayed GOAT activity in increasing concentrations of ethanol. Ethanol was tested at concentrations representing intracellular ethanol levels ranging from subintoxicating $(1 \mathrm{mM})$ to grossly intoxicating, lethal $(87 \mathrm{mM})$ doses $[69,70]$. We found that ghrelin acylation by GOAT was not dose-dependently inhibited by ethanol over this physiologically relevant concentration range, with less than $20 \%$ inhibition observed at the highest concentration tested (Figure S5).

\subsection{Plasma Ghrelin Levels in Rats Are Differentially Affected by Ethanol and Sucrose}

Our experiments, thus far, indicated that while ethanol decreases acyl-ghrelin secretion in humans and animals, no direct interaction between ethanol and the ghrelin system (acyl-ghrelin secretion from gastric mucosal cells, GOAT activity, or ghrelin receptor KO) was observed in our aforementioned experiments. We hypothesized that the effect of ethanol to lower peripheral ghrelin concentrations in humans and animals may have occurred indirectly, in proportion to caloric load. We compared the effect of ethanol (1.5 g/kg, $\sim 10 \mathrm{kcal} / \mathrm{kg}$ i.p. $)$ with a sucrose solution $(2.8 \mathrm{~g} / \mathrm{kg}, \sim 11.2 \mathrm{kcal} / \mathrm{g}$ i.p. $)$ of similar caloric value in male rats, on acyl- and des-acyl-ghrelin in a within-subjects comparison to saline treatment on the previous day. 
As for ethanol, we observed a significant main effect of treatment (ethanol vs. saline) on acylghrelin levels $[\mathrm{F}(1,18)=7.83, \mathrm{p}=0.02]$, and a treatment $\times$ time interaction effect $[\mathrm{F}(2,36)=18.09, \mathrm{p}<$ 0.0001], but no main effect of time. Post-hoc testing revealed a decrease in acyl-ghrelin levels following ethanol treatment, compared to baseline, and in comparison with saline (Figure 6A, left). For des-acylghrelin, significant main effects of treatment $[\mathrm{F}(1,18)=5.253, \mathrm{p}=0.034]$ and time $[\mathrm{F}(1.673,30.12)=$ 3.799, $\mathrm{p}=0.041]$, as well as treatment $\times$ time interaction effect $[\mathrm{F}(2,36)=3.301, \mathrm{p}=0.048]$ were observed. Post-hoc testing revealed significant increase in des-acyl-ghrelin levels following saline treatment, but no changes following ethanol treatment (Figure 6A, right). There was also a significant main effect of treatment $[\mathrm{F}(1,18)=10.68, \mathrm{p}=0.0043]$, time $[\mathrm{F}(2,36)=59.03, \mathrm{p}<0.0001]$, and interaction $[\mathrm{F}(2,36)=50.02, \mathrm{p}<0.0001]$ on the acyl- to des-acyl-ghrelin ratio (AG:DAG ratio). Post-hoc testing revealed significant reduction in AG:DAG ratio following ethanol treatment, but no changes following saline treatment (Figure S6).

As for sucrose, we observed an overall significant main effect of treatment (sucrose vs. saline) $[F(1,16)=7.705, p=0.01]$ on acyl-ghrelin levels, but no effect of time or an interaction effect, indicating lower levels of acyl-ghrelin under sucrose treatment, compared to saline, regardless of time (Figure 6B, left). There was no effect of treatment or treatment $\times$ time interaction on des-acyl-ghrelin levels, but a significant effect of time $[\mathrm{F}(1.839,29.43)=20.11, \mathrm{p}<0.0001]$ was observed, with post-hoc testing indicating an overall increase in des-acyl-ghrelin over time (Figure 6B, right). Lastly, we observed a significant main effect of treatment $[\mathrm{F}(1,16)=4.93, \mathrm{p}=0.041]$, time $[\mathrm{F}(1.966,31.45)=26.38, \mathrm{p}<$ 0.0001], and treatment $\times$ time interaction $[\mathrm{F}(2,32)=19.18, \mathrm{p}<0.0001]$ on the AG:DAG ratio. Post-hoc testing revealed significant reduction in AG:DAG ratio following sucrose treatment, but no, or less robust, changes following saline treatment (Figure S6).

\section{Discussion:}


The results presented herein demonstrate ethanol administration acutely suppressed both plasma acyl- and total ghrelin levels in humans and rats. While these findings are consistent with previous preliminary work $[2,52-56]$, they expand our knowledge of the effect of ethanol on ghrelin by providing evidence that this effect occurs independently of the ghrelin receptor, given that ethanol-induced suppression of acyl-ghrelin is observed despite knockout of the ghrelin receptor in rats. Moreover, AUD (associated with long term ethanol use) had no effect on central ghrelin, ghrelin receptor, or GOAT enzyme mRNA expression in select brain regions. Our results also show that the effect of ethanol on acylghrelin secretion does not occur through inhibition of GOAT activity or direct inhibition of gastric mucosal cell secretion of acyl-ghrelin. Moreover, administration of ethanol in comparison to sucrose solution produces distinct effects on peripheral ghrelin, despite similar caloric value. Overall, our data suggest that the mechanism by which ethanol intake suppresses plasma ghrelin is indirect and is not necessarily proportional to caloric load.

We consistently observed a reduction in both acyl-ghrelin and total ghrelin in all four experiments, despite each session employing a different duration, dose of alcohol, and type of alcoholic beverage. Our findings further demonstrate that alcohol administration results in acute suppression of peripheral ghrelin, regardless of the route of administration being oral or intravenous and is therefore irrespective of first-pass metabolism. As such, our work strengthens the suggestion that passage through the stomach is not necessary for acute alcohol-induced ghrelin suppression [56, 57]. We did not observe a statistically significant reduction in acyl- or total ghrelin during the fixed IV administration of alcohol. However, here, we were only able to examine ghrelin levels within $45 \mathrm{~min}$ following the start of the session. While other sessions with more timepoints collected revealed that alcohol can significantly decrease acyl-ghrelin within $30 \mathrm{~min}$, the experiment was likely insufficiently powered to detect a change that reached statistical significance within such a short time window. Total ghrelin followed the same trends as acyl-ghrelin for all sessions. Given that we did not have data on des-acyl-ghrelin levels at these 
timepoints, it is unclear whether the reduction in total ghrelin is mainly reflective of a reduction of acylghrelin, or a reduction of both acyl- and des-acyl-ghrelin in these samples.

Data from Ghsr KO and WT rats indicate that intraperitoneal injection of ethanol has no rapid, acute effect on des-acyl-ghrelin and only reduces acyl-ghrelin 15 min post-injection. Moreover, we found that this effect of ethanol on acyl-ghrelin occurred independently of the presence or absence of the ghrelin receptor. Although these results may be due to compensatory mechanisms formed during development, we also show no change in central ghrelin, GOAT, or ghrelin receptor expression as a result of chronic exposure to alcohol in individuals with severe AUD (human post-mortem sample). More specifically, GHRL, GHSR, and MBOAT4 mRNA expression levels were not statistically different (after correcting for multiple comparisons) between post-mortem brain samples from individuals with AUD and non-AUD controls, indicating that chronic alcohol exposure does not directly affect central ghrelin system expression in these brain regions. However, given that GHSR is not highly expressed in the hippocampus, amygdala, PFC, VTA, or NAc, and that our sample size was relatively small, we may not have been able to precisely capture any effect of long-term ethanol use on the ghrelin receptor that was statistically meaningful. It should also be considered that the expression of GHSR produces two transcripts, GHSR1a and GHSR1b, the latter of which heterodimerizes with and attenuates GHSR1a [71]. Likewise, expression of GHRL can also produce products other than pro-ghrelin [71]. Therefore, these findings are not restricted to ghrelin and its receptor. Furthermore, the significance of central GHRL mRNA expression remains to be determined. While some GHRL mRNA is found in the brain, and central GHRL mRNA translation has been demonstrated in rodents, it remains to be demonstrated whether $G H R L$ is centrally translated in humans, with the more significant sites of GHRL expression being the stomach and duodenum [72]. Still, our data from rodents and human post-mortem samples provide converging, albeit preliminary, evidence that the ghrelin receptor does not play a mediating role in acute alcohol-induced suppression of ghrelin. 
In vitro assay with the GOAT enzyme, a ghrelin mimetic peptide, and octanoate-CoA revealed no dose-dependent effects of ethanol on GOAT acylation activity. These data indicate that alcohol does not mediate its effects on ghrelin secretion by negatively allosterically modifying or directly inhibiting GOAT acylation activity by interfering with GOAT substrate binding. Moreover, gastric mucosal cell secretion of acyl-ghrelin was unaffected by incubation with ethanol either alone or in the presence of glucose. Cells were also tested in the presence of glucose to eliminate the presence or absence of an energy source as a confounding variable in acyl-ghrelin secretion. As reported previously, absence of glucose increased ghrelin secretion $[67,73]$, and ethanol had no effect on ghrelin in either condition. We only evaluated secretion of acyl-ghrelin from gastric mucosal cells and did not evaluate any changes in des-acyl-ghrelin, however, from our rodent data, it appears that alcohol primarily suppresses acyl-ghrelin secretion. Taken together, our in vitro and ex vivo data point toward an indirect mechanism whereby alcohol suppresses peripheral ghrelin levels.

Previous studies have suggested that post-prandial ghrelin suppression occurs in proportion to caloric load and that this may underlie alcohol-induced ghrelin suppression [74-76]. Here, we show that acyl-ghrelin was significantly decreased as a result of ethanol administration both 15- and 60-min following injection compared to baseline, whereas there was no significant change in des-acyl-ghrelin following ethanol treatment between each time point. Following sucrose treatment, there was no change in acyl-ghrelin relative to baseline, but des-acyl-ghrelin was significantly increased relative to baseline at 15- and 60-min. Interestingly, given these effects, ethanol and sucrose had similar effects on the AG:DAG ratio, where a decrease of acyl-ghrelin by ethanol, and an increase of des-acyl-ghrelin by sucrose both decreased the plasma AG:DAG ratio significantly at 15 and 60-min post injection. Both acyl- and desacyl-ghrelin increased over time among saline treated controls. Relative to saline, acyl-ghrelin was decreased by ethanol, and the increase in des-acyl-ghrelin observed following saline treatment was blunted by ethanol. Sucrose treatment, however, blunted the increase in acyl-ghrelin among saline treated controls and did not change the increase in des-acyl-ghrelin relative to saline. It is possible that the 
increase in acyl- and des-acyl-ghrelin following saline treatment represents a fasting-induced increase in ghrelin that is differentially affected by ethanol and sucrose. Our data showing that ghrelin is not suppressed in proportion to caloric value alone are supported by studies in humans demonstrating that administration of one type of macronutrient differentially affects ghrelin secretion when compared to a different macronutrient of equivalent caloric value [77, 78]. Moreover, acyl-ghrelin is not dosedependently decreased by higher doses of IV ethanol (associated with higher caloric value) [57]. Our data also suggest that ghrelin acylation and ghrelin peptide secretion are regulated by separate mechanisms, given the markedly different effects of alcohol and sucrose on these different forms of ghrelin. Acylghrelin plays an important role in relaying meal-related information [79], and it is likely that differences in post-prandial (or post-alcohol) acyl-ghrelin secretion are not simply reflective of calorie content, but represent a more complicated summation of the metabolic effects resulting from a meal or alcohol on energy homeostasis, which can vary according to macronutrients, meal status, and size of meal.

Thus, we report here novel findings on the potential underlying mechanism(s) linking alcohol and the ghrelin system. Our results suggest that an indirect mechanism underlies alcohol-induced suppression of acyl-ghrelin that is unique to alcohol. This finding is not surprising given that alcohol's inability to be stored causes it to be immediately metabolized in the liver at the expense of other nutrients, competitively inhibiting liver enzymes and depleting the pool of electrons used in oxidation of other nutrients [80]. Therefore, it is likely that the downstream effects of alcohol occur on a faster timescale than other macronutrients, depending on prandial state. We observed reductions in acyl-ghrelin within 15 min following alcohol administration in our rodent experiments, and as early as $30 \mathrm{~min}$ in our human experiments, whereas post-prandial reductions in ghrelin reaching statistical significance typically occur between 1-2 $\mathrm{h}$ following meal ingestion. Although we did not identify a mechanism by which alcohol suppresses acyl-ghrelin, our data shed further light on the complicated nature of ghrelin-alcohol interplay. Acyl-ghrelin is an important component in the regulation of energy balance by signaling for meal preparation and having long-term protective effects against starvation [26, 27]. To date, models of acyl- 
ghrelin secretion have identified insulin, glucagon, long chain fatty acids, oxytocin, dopamine, norepinephrine, epinephrine, endocannabinoids, somatostatin, glutamate, and glucose as direct regulators of acyl-ghrelin secretion [73, 81-87], and it is possible that alcohol may decrease acyl-ghrelin indirectly by affecting these targets. Another possibility is that alcohol-induced suppression of acyl-ghrelin results from alcohol's marked acute inhibition of fatty acid $\beta$-oxidation. [80]. Recently, it has been suggested that ghrelin acylation can be supported by $\beta$-oxidation of long chain fatty acids to produce medium chain fatty acids able to act as GOAT substrates [83, 86, 88]. Therefore, alcohol-induced inhibition of $\beta$-oxidation may be partly responsible for acyl-ghrelin suppression resulting from alcohol intake. Clearly, further studies are needed to identify whether these or other mechanisms, such as indirect suppression through other hormones affected by alcohol, underlie the acute alcohol-ghrelin relationship.

Overall, this set of results contributes to a better understanding of the complex interactions between alcohol and the ghrelin system. Nevertheless, these results should be interpreted in light of the study's limitations. Data presented from human laboratory experiments are the result of secondary analyses and were, therefore, not designed a priori to evaluate the effect of alcohol on peripheral ghrelin (e.g., no control infusion/oral saline administration was performed to compare to alcohol). Additionally, the sample sizes from our human and post-mortem experiments are small. Our findings on the central expression of GHRL, GHSR, and MBOAT4 in humans should be further investigated in larger samples. We were unable to evaluate expression of these genes in the hypothalamus, a prominent site of central acyl-ghrelin action that might be more significantly altered by chronic exposure to alcohol. Lastly, it should be noted that our results can currently only be generalized to males, given that the human laboratory experiment samples (all $>70 \%$ male) were largely male, and human post-mortem samples and animals, used in ethanol administration experiments and for gastric mucosal experiments, were all male.

Our data collectively demonstrate that alcohol affects the ghrelin system by acutely decreasing acyl-ghrelin concentration in the circulation and by blunting fasting-induced increase of plasma des-acylghrelin concentrations, and the mechanism likely occurs independently of the ghrelin receptor, and 
without direct action on the GOAT enzyme or acyl-ghrelin secretion from gastric mucosal cells. Additionally, ethanol and sucrose in equivalent caloric amounts do not have the same effect on peripheral ghrelin, differentially affecting acyl- and des-acyl-ghrelin relative to baseline and saline-treated controls. Therefore, this study suggests that alcohol acutely suppresses ghrelin without directly interacting with the ghrelin system and not simply according to calorie content of alcohol. While further studies are needed to uncover this mechanism of alcohol-induced ghrelin suppression, our data provide new insight into how these effects occur.

\section{Methods and Materials:}

\subsection{Effects of Alcohol on Peripheral Ghrelin Levels in Humans}

To examine the effect of alcohol on endogenous ghrelin levels, we performed separate analyses of four human laboratory experiments conducted by our team at the National Institutes of Health (NIH) Clinical Center in Bethesda, Maryland. These experiments were originally performed as part of three placebo-controlled trials [49, 65, 66] (ClinicalTrials.gov: NCT02039349, NCT01779024, $\underline{\text { NCT01751386) }}$ and included the administration of alcohol to non-treatment-seeking, heavy-drinking individuals, as well as measurement of plasma ghrelin levels. Here, we only included data from the placebo conditions of these experiments. Participants provided informed consent and were compensated for participating in each study. The eligibility criteria of each parent study can be found in the Supplementary Information (S1A, S2A, S3A) and baseline characteristics of each sample analyzed here can be found in Table S1. We analyzed data separately for each of the following experiments: (1) variable dose (priming and selfadministration) oral alcohol [65], (2) fixed-dose oral alcohol [66], (3) IV variable dose (selfadministration) alcohol [49], and (4) fixed-dose intravenous (IV) alcohol [49]. Detailed descriptions of these studies and their primary outcomes have been previously reported $[49,65,66]$. Descriptions of standardized meals for each study can be found in the supplement (S1B, S2B, S3B). An overview of these 
experiments, including information about times of blood draws, meals, and alcohol administration can be found in Figure 1 and Table S2. Below we provide a brief description of each experiment.

\subsubsection{Oral Variable Dose Alcohol Administration}

The main aim of the parent study was to test the role of baclofen on alcohol drinking using a randomized, between-subjects, double-blind, placebo-controlled human laboratory design [65]. Here, we analyzed data from the placebo group only (participants randomized to placebo and not baclofen). Participants received their assigned study medication (placebo only in this analysis) for approximately a week before returning to complete the experimental session. Participants were instructed to abstain from alcohol $24 \mathrm{~h}$ prior to the experiment (verified by $\mathrm{BrAC}=0 \mathrm{~g} / \mathrm{dL}$ ) and to take their first medication dose before arriving at the clinic. The experimental session consisted of alcohol cue reactivity followed by alcohol priming and alcohol self-administration (for full details, see: [65]). Briefly, for the alcohol priming, participants were provided with their preferred choice of alcohol, mixer (S1C, S2C), and television program. The amount of alcohol in the priming drink was calculated to raise each participant's BAC to $0.03 \mathrm{~g} / \mathrm{dL}$ [89]. Participants were asked to consume the entire drink within five min. The alcohol self-administration (ASA) session began 40 min after consumption of the priming drink. At the beginning of the ASA session, a tray containing four mini-drinks was offered. Each mini-drink had half the amount of alcohol as the priming drink (BAC increase of $0.015 \mathrm{~g} / \mathrm{dL}$ ), and participants were allowed to drink as many of the mini-drinks as they chose, with the knowledge that they would receive $\$ 3$ for each mini-drink not consumed. An additional tray with 4 mini-drinks was offered again 60 min after the beginning of the ASA session. The total ASA session lasted for 120 min, during which participants were not allowed to exceed a BAC of $0.12 \mathrm{~g} / \mathrm{dL}$, and BrAC and vital signs were collected every $30 \mathrm{~min}$. Following completion of the ASA session, participants were escorted to an inpatient unit where they were monitored until BrAC reached $0 \mathrm{~g} / \mathrm{dL}$, and they were discharged the next morning.

\subsubsection{Oral Fixed-Dose Alcohol Administration}


The main aim of the parent study was to test the safety of a ghrelin receptor blocker (PF5190457), co-administered with alcohol, using a Phase 1b, within-subjects, dose-escalating, single-blind, placebo-controlled human laboratory design [66]. Here, we analyzed data from the placebo condition only. The alcohol administration experiment was held on the third day of an inpatient visit, after taking five doses of the study drug (placebo only in this analysis). A standardized alcoholic beverage (Smirnoff vodka, $40 \%$ alcohol by volume; $80 \%$ proof) was administered, and participants were instructed to drink the beverage within $15 \mathrm{~min}$. Alcohol was provided as a mixed drink containing the participants' choice from a list of 7 common mixers (S1C). Alcohol administration was designed to bring each participant's blood alcohol concentration to a target BAC of $0.06 \mathrm{~g} / \mathrm{dL}$ [89].

\subsubsection{Fixed Dose IV Administration of Ethanol and IV-Alcohol Self-Administration}

The parent study under which both IV-alcohol experiments were performed was a cross-over, randomized, double-blind, placebo-controlled study testing the effects of exogenous ghrelin administration and consisting of four experimental sessions: two IV ASA (1 ghrelin, 1 placebo) sessions and two brain fMRI sessions (1 ghrelin, 1 placebo). We analyzed data from the placebo sessions only. Participants were admitted to the NIAAA inpatient unit at the NIH Clinical Center on the evening before each experiment day. Before each experiment, an IV catheter was inserted into each arm (one for ghrelin/placebo and one for alcohol infusion/blood sampling). For the placebo conditions (which are the only ones considered in this analysis), saline solution was infused during the entire experiment. IV Alcohol was given as $100 \%$ dehydrated ethanol diluted by saline to $6.0 \%(\mathrm{v} / \mathrm{v})$.

\subsubsection{IV-ASA Experimental Session}

For the IV-ASA experiment, participants were given the opportunity to press a button to receive IV-alcohol infusions using a Computerized Alcohol Infusion System (CAIS) during a 120-min session. A progressive-ratio schedule for self-administration was applied, which required the participants to press the button an increasing number of times to receive the subsequent alcohol infusion. Incremental infusion rates were calculated individually to raise each participants BAC to $0.0075 \mathrm{mg} / \mathrm{dL}$ within two min [89]. 
BrAC measurements were taken every 15 min throughout the procedure and entered in CAIS software for model-based algorithm adjustments and BAC prediction. Participants were not allowed to exceed a BrAC of $0.12 \mathrm{~g} / \mathrm{dL}$ during the ASA session. For additional detail, please see: [49, 90, 91]

\subsubsection{Fixed Dose IV-Administration Experiment}

The fixed-dose IV-alcohol administration was conducted as part of a brain fMRI experiment in which subjects completed an alcohol-food incentive delay (AFID) task that exposed participants to food, alcohol, and neutral symbols. After the loading dose, participants completed an initial AFID task without exposure to alcohol. Participants then received continuous IV alcohol infusion while they repeated the resting state scan and AFID task again. The alcohol infusion was given to raise each participant's BrAC linearly to $0.08 \mathrm{~g} / \mathrm{dL}[89]$, within $20 \mathrm{~min}$, and clamp the $\mathrm{BrAC}$ at this target value until the end of the experiment. The total duration of the IV alcohol infusion was $35 \mathrm{~min}$. For additional detail, please see $[49,90,91]$.

\subsubsection{Clinical Blood Collection, Processing, and Assay of Ghrelin Levels}

For each experiment listed above, blood was collected at multiple time points throughout each experimental session to allow for repeated measures of plasma acyl- and total-ghrelin levels (Figure 1, Table S2). The full technical details for blood collection, plasma extraction, and acyl and total ghrelin assays for each study can be found in the Supplement (S1D, S2D, S3C).

\subsection{GHSR, GHRL, and MBOAT4 Gene Expression in Human Post-mortem Brain Tissue}

Expression levels of the ghrelin receptor gene $(G H S R)$, ghrelin gene $(G H R L)$, and GOAT gene (MBOAT4) were analyzed in post-mortem brain samples from male subjects diagnosed with severe alcohol use disorder (AUD) (DSM-5) and controls who did not have a diagnosis of AUD. Human postmortem brain tissue was obtained from the New South Wales Tissue Resource Centre (NSWBTRC) at the University of Sydney, Australia [92]. GHSR, GHRL, and MBOAT4 RNA extraction, reverse transcription, and qPCR analysis were performed using procedures previously reported [93]. mRNA was extracted from 
the five available brain regions, including amygdala, hippocampus, VTA, NAc, and PFC (superior frontal Brodmann areas 8 and 9). Full technical details can be found in the Supplementary Information (S4).

\subsection{Effects of Ethanol Administration on Peripheral Ghrelin Levels in Ghsr KO and WT Rats}

Male WT and Ghsr KO (Wistar background) rats weighing 350 - 850g were obtained from the Transgenic Breeding Facility at the National Institutes on Drug Abuse (NIDA) Intramural Research Program (IRP) (Baltimore, MD, USA). The development and characterization of the Ghsr KO rat has been previously described [94]. Animals were single-housed and maintained in temperature-controlled facilities on a $12 \mathrm{~h} / 12 \mathrm{~h}$ light cycle with standard chow and water available ad libitum. Rats from both genotype groups randomly received either ethanol (20\% w/v) and saline: $(1)$ Ghsr KO - Alcohol $(\mathrm{n}=8)$,

(2) Ghsr KO - Saline (n = 9), (3) WT - Alcohol (n = 9), and (4) WT - Saline (n = 8). Rats were given an intraperitoneal (i.p.) injection of either $(1.5 \mathrm{~g} / \mathrm{kg}, 7.5 \mathrm{ml} / \mathrm{kg})$ or saline $(1 \mathrm{ml} / \mathrm{kg}) 15 \mathrm{~min}$ before collection of trunk blood into EDTA coated tubes containing inhibitors appropriate for acyl-ghrelin/des-acyl-ghrelin measurement. Full technical details of processing and assay can be found in the Supplementary Information (S5).

\subsection{The Effect of Ethanol on Ghrelin Secretion from Gastric Mucosal Cells}

Gastric mucosal cells were isolated and established from 8-12 wk-old male C57BL/6N mice as reported previously $[68,73]$, and then supplemented with sodium octanoate-bovine serum albumin (BSA) before they were treated with medium containing different ethanol concentrations. After incubation, mediums were assayed for acyl-ghrelin by ELISA. Full technical details can be found in the Supplementary Information (S6).

\subsection{Effect of Ethanol on Human GOAT (hGOAT) Ghrelin Acylation Activity}

Assays were performed with $70 \mu \mathrm{g}$ membrane protein from Sf9 cells expressing hGOAT, as determined by Bradford assay. Each ethanol concentration was tested by adding an ethanol stock to a mix of HEPES, membrane protein, and MAFP before initiating reactions with octanoyl-coA and GSSFLC AcDan $_{\text {. }}$ 
peptide. Reactions were stopped after $1 \mathrm{hr}$ with acetic acid, and the medium was analyzed using reversephase HPLC, as described previously $[95,96]$. GOAT acylation activity was determined by substrate and product peak integration in the presence of either ethanol or water (vehicle). Percent activity for each reaction was calculated using equations 1 and 2 [97]. Full technical details can be found in the Supplementary Information (S7).

(1) $\%$ peptide octanoylation $=\frac{\text { fluorescence of octanoylated peptide }}{\text { total peptide fluorescence (substrate and product) }}$

(2) $\%$ activity $=\frac{\% \text { peptide octanoylation in presence of inhibitor }}{\% \text { peptide octanoylation in absence of inhibitor }}$

\subsection{Effects of Ethanol Administration on Peripheral Ghrelin Levels in Rats}

Male Wistar rats 10-12 months old (400-700 g) were obtained from Charles River Laboratory (Wilmington, MA). Animals were single-housed and maintained in temperature-controlled facilities on a $12 \mathrm{~h} / 12 \mathrm{~h}$ light cycle with standard chow and water available ad libitum. Prior to the experiment, rats were habituated to i.p. injections for three days by performing daily saline injections. On the day before the experiment, rats were also habituated to the testing room for $1 \mathrm{~h}$. The following day, baseline measures for each rat were collected via tail bleed 6-7 $\mathrm{h}$ into the light cycle, at 15 and $60 \mathrm{~min}$, following saline injection $(1 \mathrm{ml} / \mathrm{kg}$, i.p.). Rats were returned to their home cages in between injection and blood draws. Food and water remained accessible to the rats in the home cages. The following day, rats were divided into two groups and received either $20 \% \mathrm{w} / \mathrm{v}$ ethanol $(1.5 \mathrm{~g} / \mathrm{kg}, 7.5 \mathrm{ml} / \mathrm{kg}$, i.p. $)$ or $35 \% \mathrm{w} / \mathrm{v}$ sucrose $(2.8$ $\mathrm{g} / \mathrm{kg}, 8 \mathrm{ml} / \mathrm{kg}$, i.p.). Tail blood was again drawn at the 0,15 , and $60 \mathrm{~min}$ timepoints, and processed as described in Experiment 3.3.(S5).

\subsection{Statistics}

Human laboratory experiments: outliers (defined as outside of $\pm 1.5(\mathrm{IQR})$ per hormone per timepoint) were removed. Data were analyzed using Linear Mixed Effects Models in SPSS 25 (IBM Corporation, Armonk, NY) and were evaluated for random effect of subject, main effect of time point, 
and covariates (age, gender, BMI, and race) on acyl- or total ghrelin. Random effects were described with a scaled identity covariance structure. Covariates that were not significant in the initial run of each model were removed from the final model. Post-hoc analyses were performed using pairwise comparisons of group means at each timepoint within an experiment, and Bonferroni correction was used to conservatively control for multiple comparisons. Human post-mortem experiment: Human post-mortem data were analyzed using Linear Mixed Effects Models in SPSS 25 and were evaluated for random effect of subject, fixed effect of group (AUD, Non-AUD), and covariates (Post-mortem interval (PMI), age, brain weight, brain $\mathrm{pH}, \mathrm{BMI}$, and cigarette pack years) on fold change $\left(2^{-\Delta \Delta \mathrm{Ct}}\right)$ mRNA expression in each brain region. Covariates that were not significant in the initial run of each model were removed from the final model. A variance components covariance structure was used to describe random effects. To conservatively control for multiple comparisons, Bonferroni correction was applied to correct for the number of brain regions tested. Ethanol experiments with $K O$ and WT rats: A two-way ANOVA was used to evaluate genotype (KO vs. WT), treatment (ethanol vs. saline), and genotype $\mathrm{x}$ treatment interaction main effects among saline and ethanol treated Ghsr KO and WT rats in GraphPad Prism. Tukey's multiple comparison test was used to evaluate differences in group means between all genotype and treatment groups. Gastric mucosal cell experiments: For ghrelin secretion studies in gastric mucosal cells, a one-way ANOVA followed by Dunnet's test was used to analyze the effect of different concentrations of ethanol on acyl-ghrelin secretion in Graph Pad Prism. Ethanol and sucrose experiment with rats: Lastly, two-way repeated measures ANOVA was used to evaluate treatment (ethanol vs. saline and sucrose $v s$. saline), time $(0,15$, and $60 \mathrm{~min})$, and treatment $\mathrm{x}$ time interaction main effects on acylghrelin and des-acyl-ghrelin in rats using GraphPad Prism. Sidak's multiple comparison test was used for post-hoc analyses. For all analyses, significance was set at $\mathrm{p}<0.05$.

\subsection{Approvals}

Human laboratory experiments were approved by the NIH Addictions Institutional Review Board, registered at ClinicalTrials.gov (NCT02039349, NCT01779024, NCT01751386), reviewed by the 
FDA if applicable under Investigational New Drug (IND) applications, and conducted in accordance with Declaration of Helsinki principles. All participants provided written informed consent before any protocol-specific research procedure took place. The human post-mortem brain project was approved by the NIAAA Scientific Advisory Board and the NIH Office of Human Subjects Research Protections and was exempt from review by the NIH Institutional Review Board. Animal studies performed at the NIH IRP adhered to the National Research Council Guide for the Care and Use of Laboratory Animals and were approved by the Institutional Animal Care and Use Committee of the NIDA IRP. All animal procedures and use of mice at UT Southwestern Medical Center (UTSW) were approved by the Institutional Animal Care and Use Committee of UTSW.

\section{Author Contributions:}

Overall study basis, rationale and concept: LL

Design of the experiments: 1) current analyses from the human laboratory experiments (MF, LL), 2) in vivo rodent experiments (MF, AGF, LJZ, RCNM, BJT, GFK, LFV, LL); 3) ex vivo experiments in gastric mucosal cells (JMZ); 4) in vitro assays of GOAT enzyme activity (JEM, MR, JLH).

Acquisition and management of data: 1) human laboratory experiments (MF, SLD, MRL, FA, LL), 2) post-mortem experiments (MF, SLD, HS, MRL), 3) in vivo rodent experiments (AGF, LJZ, RCNM, BJT, LFV); 4) ex vivo experiments in gastric mucosal cells (BKM, JMZ); 5) in vitro assays of GOAT enzyme activity (JEM); 6) human ghrelin assays (FA); and 7) rodent ghrelin assay (ZBY).

Analysis and interpretation of data: 1) human laboratory experiments (MF, SLD, LL), 2) post-mortem experiments (MF, SLD, LL), 3) in vivo rodent experiments (MF, SLD, AGF, LJZ, RCNM, BJT, GFK, LFV, LL); 4) ex vivo experiments in gastric mucosal cells (BKM, MR, JMZ); 5) in vitro assays of GOAT enzyme activity (JEM, MR, JLH); 6) human ghrelin assays (MF, SLD, FA, LL); and 7) rodent ghrelin assay (MF, SLD, AGF, LJZ, RCNM, BJT, GFK, LFV, LL) 
Clinical and safety monitoring for the human studies: MRL, LL

Provided funding: FA, JLH, JMZ, GFK, LL

Drafting the manuscript: SLD

Assisted with drafting the manuscript: MF, DMH, LL

All authors have critically reviewed the manuscript for important intellectual content and approved the final version of the manuscript.

\section{Funding:}

The human laboratory studies were supported by the NIH intramural funding ZIA-AA000218 (Clinical Psychoneuroendocrinology and Neuropsychopharmacology Section - PI: LL), jointly supported by the NIDA Intramural Research Program and the NIAAA Division of Intramural Clinical and Biological Research. The rodent studies were supported by the NIDA IRP Neurobiology of Addiction Section (PI: GFK) and by the NIDA/NIAAA joint Clinical Psychoneuroendocrinology and Neuropsychopharmacology Section (PI: LL).

The development of the Computerized Alcohol Infusion System (CAIS) software used in the IV ghrelin study was supported by Dr. Vijay Ramchandani's Section on Human Psychopharmacology in the NIAAA Division of Intramural Clinical and Biological Research and by the NIAAA-funded Indiana Alcohol Research Center (AA007611). The PF-5190457 phase 1b study received additional funding from the National Center for Advancing Translational Sciences (NCATS), under an UH2/UH3 grant (TR000963 PIs: LL and FA). Pfizer kindly provided the PF-5190457 compound under the NCATS grant UH2/UH3TR000963. Pfizer did not have any role in the study design, execution or interpretation of the results, and this publication does not necessarily represent the official views of Pfizer. The baclofen study received additional finding from the Brain and Behavior Research Foundation (BBRF; formerly NARSAD) grant number 17325 (PI: LL). Brain tissues were received from the New South Wales Brain Tissue Resource 
Centre (NSWBTRC) at the University of Sydney, which is supported by NIAAA under Award Number R28AA012725 and Neuroscience Research Australia. The GOAT enzyme activity studies were supported by NIGMS under grant R01GM134102 (PI: JLH). MF and RCNM are fellows of the Center for Compulsive Behaviors at NIH. BJT was additionally supported by NIH award DA048530. The ex vivo experiments in gastric mucosal cells were supported by a NIH extramural grant R01DK103884 (PI: JMZ).

\section{Acknowledgements:}

We thank the clinical and research staff involved in patient care, data collection/analysis, and technical support in the joint NIDA/NIAAA Clinical Psychoneuroendocrinology and Neuropsychopharmacology

Section, in the NIAAA clinical program of the Division of Intramural Clinical and Biological Research (DICBR) (in particular the NIAAA Office of the Clinical Director and the NIAA Clinical Core Laboratory), at the NIH Clinical Center (Departments of Nursing, Nutrition, and Pharmacy), and in the Clinical Pharmacokinetics Research Laboratory at the University of Rhode Island.

We would also like to thank Dr. Melanie Schwandt (Office of the Clinical Director, NIAAA) for data management. We would like to thank Dr. Vijay Ramchandani (Section on Human Psychopharmacology, NIAAA DICBR) and Dr. Reza Momenan (Clinical NeuroImaging Research Core, NIAAA DICBR) for their support in the execution of the parent studies from which these analyses stemmed. The authors would also like to express their gratitude to the participants who took part in these studies. We would like to thank the members of the Neurobiology of Addiction Section, the Transgenic Breeding Facility and the Genetic Engineering and Viral Vector Core in the Intramural Research Program at NIDA/NIH involved in animal care and technical support. Finally, the authors would like to thank Ms. Donna Sheedy and Dr. Jillian Kril from the New South Wales Tissue Resource Centre (NSWBTRC) at the University of Sydney, Australia, for providing the human post-mortem brain tissue for this project. The content of this article is 
bioRxiv preprint doi: https://doi.org/10.1101/2020.07.30.228494; this version posted July 31, 2020. The copyright holder for this preprint (which was not certified by peer review) is the author/funder. This article is a US Government work. It is not subject to copyright under 17 USC 105 and is also made available for use under a CCO license.

solely the responsibility of the authors and does not necessarily represent the official views of the National Institutes of Health.

\section{Conflict of Interest:}

The authors declare that they have no competing conflicts of interest. 


\section{References:}

1. SAMSHA. 2018 National Survey on Drug Use and Health (NSDUH). Table 5.4A-Alcohol Use Disorder in Past Year among Persons Aged 12 or Older, by Age Group and Demographic Characteristics: Numbers in Thousands, 2017 and 2018. Available from: https://www.samhsa.gov/data/sites/default/files/cbhsqreports/NSDUHDetailedTabs2018R2/NSDUHDetTabsSect5pe2018.htm\#tab5-4a.

2. (CDC), C.f.D.C.a.P. Alcohol and Public Health: Alcohol-Related Disease Impact (ARDI). Average for United States 2006-2010 Alcohol-Attributable Deaths Due to Excessive Alcohol Use. [cited 2020 5/13/2020]; Available from: https://nccd.cdc.gov/DPH ARDI/Default/Report.aspx?T=AAM\&P=f6d7eda7-036e-4553-99689b17ffad620e\&R=d7a9b303-48e9-4440-bf47-070a4827e1fd\&M=8E1C5233-5640-4EE8-92471ECA7DA325B9\&F=\&D=.

3. Engel, J.A. and E. Jerlhag, Role of appetite-regulating peptides in the pathophysiology of addiction: implications for pharmacotherapy. CNS Drugs, 2014. 28(10): p. 875-86.

4. Fletcher, P.C. and P.J. Kenny, Food addiction: a valid concept? Neuropsychopharmacology, 2018. 43(13): p. 2506-2513.

5. Volkow, N.D., et al., Food and drug reward: overlapping circuits in human obesity and addiction. Curr Top Behav Neurosci, 2012. 11: p. 1-24.

6. Farokhnia, M., et al., Ghrelin: From a gut hormone to a potential therapeutic target for alcohol use disorder. Physiol Behav, 2019. 204: p. 49-57.

7. Koopmann, A., R. Schuster, and F. Kiefer, The impact of the appetite-regulating, orexigenic peptide ghrelin on alcohol use disorders: A systematic review of preclinical and clinical data. Biol Psychol, 2018. 131: p. 14-30.

8. Zallar, L.J., et al., The Role of the Ghrelin System in Drug Addiction. Int Rev Neurobiol, 2017. 136: p. 89-119.

9. Kojima, M., et al., Ghrelin is a growth-hormone-releasing acylated peptide from stomach. Nature, 1999. 402(6762): p. 656-60.

10. Ariyasu, H., et al., Stomach is a major source of circulating ghrelin, and feeding state determines plasma ghrelin-like immunoreactivity levels in humans. J Clin Endocrinol Metab, 2001. 86(10): p. 4753-8.

11. Zhu, X., et al., On the processing of proghrelin to ghrelin. J Biol Chem, 2006. 281(50): p. 3886770.

12. Labarthe, A., et al., Ghrelin-Derived Peptides: A Link between Appetite/Reward, GH Axis, and Psychiatric Disorders? Front Endocrinol (Lausanne), 2014. 5: p. 163.

13. Kojima, M. and K. Kangawa, Ghrelin: from gene to physiological function. Results Probl Cell Differ, 2010. 50: p. 185-205.

14. Matsumoto, M., et al., Structure-activity relationship of ghrelin: pharmacological study of ghrelin peptides. Biochem Biophys Res Commun, 2001. 287(1): p. 142-6.

15. De Vriese, C., et al., Ghrelin degradation by serum and tissue homogenates: identification of the cleavage sites. Endocrinology, 2004. 145(11): p. 4997-5005.

16. Hopkins, A.L., et al., Unacylated ghrelin promotes adipogenesis in rodent bone marrow via ghrelin O-acyl transferase and GHS-R1a activity: evidence for target cell-induced acylation. Sci Rep, 2017. 7: p. 45541.

17. Murtuza, M.I. and M. Isokawa, Endogenous ghrelin-O-acyltransferase (GOAT) acylates local ghrelin in the hippocampus. J Neurochem, 2018. 144(1): p. 58-67. 
18. Lim, C.T., et al., The expression of ghrelin O-acyltransferase (GOAT) in human tissues. Endocr J, 2011. 58(8): p. 707-10.

19. Fetissov, S.O., N. Lucas, and R. Legrand, Ghrelin-Reactive Immunoglobulins in Conditions of Altered Appetite and Energy Balance. Front Endocrinol (Lausanne), 2017. 8: p. 10.

20. Delhanty, P.J., S.J. Neggers, and A.J. van der Lely, Des-acyl ghrelin: a metabolically active peptide. Endocr Dev, 2013. 25: p. 112-21.

21. Holst, B., et al., High constitutive signaling of the ghrelin receptor--identification of a potent inverse agonist. Mol Endocrinol, 2003. 17(11): p. 2201-10.

22. Holst, B. and T.W. Schwartz, Constitutive ghrelin receptor activity as a signaling set-point in appetite regulation. Trends Pharmacol Sci, 2004. 25(3): p. 113-7.

23. Al-Massadi, O., et al., Ghrelin and LEAP-2: Rivals in Energy Metabolism. Trends Pharmacol Sci, 2018. 39(8): p. 685-694.

24. Ge, X., et al., LEAP2 Is an Endogenous Antagonist of the Ghrelin Receptor. Cell Metab, 2018. 27(2): p. 461-469 e6.

25. Mani, B.K., et al., LEAP2 changes with body mass and food intake in humans and mice. J Clin Invest, 2019. 129(9): p. 3909-3923.

26. Mani, B.K. and J.M. Zigman, Ghrelin as a Survival Hormone. Trends Endocrinol Metab, 2017. 28(12): p. 843-854.

27. Yanagi, S., et al., The Homeostatic Force of Ghrelin. Cell Metab, 2018. 27(4): p. 786-804.

28. Abizaid, A., et al., Ghrelin modulates the activity and synaptic input organization of midbrain dopamine neurons while promoting appetite. J Clin Invest, 2006. 116(12): p. 3229-39.

29. Jerlhag, E., Systemic administration of ghrelin induces conditioned place preference and stimulates accumbal dopamine. Addict Biol, 2008. 13(3-4): p. 358-63.

30. Jerlhag, E., et al., Ghrelin stimulates locomotor activity and accumbal dopamine-overflow via central cholinergic systems in mice: implications for its involvement in brain reward. Addict Biol, 2006. 11(1): p. 45-54.

31. Jerlhag, E., et al., Ghrelin administration into tegmental areas stimulates locomotor activity and increases extracellular concentration of dopamine in the nucleus accumbens. Addict Biol, 2007. 12(1): p. 6-16.

32. Jerlhag, E., et al., Concomitant release of ventral tegmental acetylcholine and accumbal dopamine by ghrelin in rats. PLoS One, 2012. 7(11): p. e49557.

33. Jiang, H., L. Betancourt, and R.G. Smith, Ghrelin amplifies dopamine signaling by cross talk involving formation of growth hormone secretagogue receptor/dopamine receptor subtype 1 heterodimers. Mol Endocrinol, 2006. 20(8): p. 1772-85.

34. Quarta, D., et al., Systemic administration of ghrelin increases extracellular dopamine in the shell but not the core subdivision of the nucleus accumbens. Neurochem Int, 2009. 54(2): p. 89-94.

35. Schellekens, H., T.G. Dinan, and J.F. Cryan, Taking two to tango: a role for ghrelin receptor heterodimerization in stress and reward. Front Neurosci, 2013. 7: p. 148.

36. Dickson, S.L., et al., The role of the central ghrelin system in reward from food and chemical drugs. Mol Cell Endocrinol, 2011. 340(1): p. 80-7.

37. Naleid, A.M., et al., Ghrelin induces feeding in the mesolimbic reward pathway between the ventral tegmental area and the nucleus accumbens. Peptides, 2005. 26(11): p. 2274-9.

38. Jerlhag, E., et al., Requirement of central ghrelin signaling for alcohol reward. Proc Natl Acad Sci U S A, 2009. 106(27): p. 11318-23.

39. Bahi, A., et al., Ghrelin knockout mice show decreased voluntary alcohol consumption and reduced ethanol-induced conditioned place preference. Peptides, 2013. 43: p. 48-55. 
40. Panagopoulos, V.N. and E. Ralevski, The role of ghrelin in addiction: a review. Psychopharmacology (Berl), 2014. 231(14): p. 2725-40.

41. Kaur, S. and A.E. Ryabinin, Ghrelin receptor antagonism decreases alcohol consumption and activation of perioculomotor urocortin-containing neurons. Alcohol Clin Exp Res, 2010. 34(9): p. 1525-34.

42. Jerlhag, E., et al., The alcohol-induced locomotor stimulation and accumbal dopamine release is suppressed in ghrelin knockout mice. Alcohol, 2011. 45(4): p. 341-7.

43. Zallar, L.J., et al., Ghrelin receptor deletion reduces binge-like alcohol drinking in rats. J Neuroendocrinol, 2019. 31(7): p. e12663.

44. Addolorato, G., et al., Relationship between ghrelin levels, alcohol craving, and nutritional status in current alcoholic patients. Alcohol Clin Exp Res, 2006. 30(11): p. 1933-7.

45. Leggio, L., et al., Intravenous ghrelin administration increases alcohol craving in alcoholdependent heavy drinkers: a preliminary investigation. Biol Psychiatry, 2014. 76(9): p. 734-41.

46. Hillemacher, T., et al., Role of appetite-regulating peptides in alcohol craving: an analysis in respect to subtypes and different consumption patterns in alcoholism. Alcohol Clin Exp Res, 2007. 31(6): p. 950-4.

47. Koopmann, A., et al., The association of the appetitive peptide acetylated ghrelin with alcohol craving in early abstinent alcohol dependent individuals. Psychoneuroendocrinology, 2012. 37(7): p. 980-6.

48. Leggio, L., et al., Ghrelin system in alcohol-dependent subjects: role of plasma ghrelin levels in alcohol drinking and craving. Addict Biol, 2012. 17(2): p. 452-64.

49. Farokhnia, M., et al., Exogenous ghrelin administration increases alcohol self-administration and modulates brain functional activity in heavy-drinking alcohol-dependent individuals. Mol Psychiatry, 2018. 23(10): p. 2029-2038.

50. Landgren, S., et al., Expression of the gene encoding the ghrelin receptor in rats selected for differential alcohol preference. Behav Brain Res, 2011. 221(1): p. 182-8.

51. Szulc, M., et al., Ethanol affects acylated and total ghrelin levels in peripheral blood of alcoholdependent rats. Addict Biol, 2013. 18(4): p. 689-701.

52. Calissendorff, J., et al., Alcohol ingestion does not affect serum levels of peptide YY but decreases both total and octanoylated ghrelin levels in healthy subjects. Metabolism, 2006. 55(12): $\mathrm{p}$. 1625-9.

53. Calissendorff, J., et al., Inhibitory effect of alcohol on ghrelin secretion in normal man. Eur J Endocrinol, 2005. 152(5): p. 743-7.

54. Calissendorff, J., et al., Alcohol intake and its effect on some appetite-regulating hormones in man: influence of gastroprotection with sucralfate. Endocr Res, 2012. 37(3): p. 154-62.

55. Zimmermann, U.S., et al., Alcohol administration acutely inhibits ghrelin secretion in an experiment involving psychosocial stress. Addict Biol, 2007. 12(1): p. 17-21.

56. Leggio, L., et al., Fasting-induced increase in plasma ghrelin is blunted by intravenous alcohol administration: a within-subject placebo-controlled study. Psychoneuroendocrinology, 2013. 38(12): p. 3085-91.

57. Ralevski, E., et al., Ghrelin is Supressed by Intravenous Alcohol and is Related to Stimulant and Sedative Effects of Alcohol. Alcohol Alcohol, 2017. 52(4): p. 431-438.

58. Kraus, T., et al., Ghrelin levels are increased in alcoholism. Alcohol Clin Exp Res, 2005. 29(12): p. 2154-7.

59. Kim, D.J., et al., Increased fasting plasma ghrelin levels during alcohol abstinence. Alcohol Alcohol, 2005. 40(1): p. 76-9. 
60. Badaoui, A., et al., Alcohol dependence is associated with reduced plasma and fundic ghrelin levels. Eur J Clin Invest, 2008. 38(6): p. 397-403.

61. de Timary, P., et al., The loss of metabolic control on alcohol drinking in heavy drinking alcoholdependent subjects. PLoS One, 2012. 7(7): p. e38682.

62. Kim, J.H., et al., The effects of alcohol abstinence on BDNF, ghrelin, and leptin secretions in alcohol-dependent patients with glucose intolerance. Alcohol Clin Exp Res, 2013. 37 Suppl 1: p. E52-8.

63. Wurst, F.M., et al., Gender differences for ghrelin levels in alcohol-dependent patients and differences between alcoholics and healthy controls. Alcohol Clin Exp Res, 2007. 31(12): p. 200611.

64. Wittekind, D.A., et al., Alcohol consumption is positively associated with fasting serum ghrelin in non-dependent adults: Results from the population-based LIFE-Adult-Study.

Psychoneuroendocrinology, 2018. 97: p. 143-148.

65. Farokhnia, M., et al., Biobehavioral effects of baclofen in anxious alcohol-dependent individuals: a randomized, double-blind, placebo-controlled, laboratory study. TransI Psychiatry, 2017. 7(4): p. e1108.

66. Lee, M.R., et al., The novel ghrelin receptor inverse agonist PF-5190457 administered with alcohol: preclinical safety experiments and a phase $1 b$ human laboratory study. Mol Psychiatry, 2018.

67. Mani, B.K., et al., Hypoglycemic Effect of Combined Ghrelin and Glucagon Receptor Blockade. Diabetes, 2017. 66(7): p. 1847-1857.

68. Mani, B.K., et al., 81-Adrenergic receptor deficiency in ghrelin-expressing cells causes hypoglycemia in susceptible individuals. J Clin Invest, 2016. 126(9): p. 3467-3478.

69. Harrison, N.L., et al., Effects of acute alcohol on excitability in the CNS. Neuropharmacology, 2017. 122: p. 36-45.

70. Roberto, M., et al., Ethanol increases GABAergic transmission at both pre-and postsynaptic sites in rat central amygdala neurons. Proc Natl Acad Sci U S A, 2003. 100(4): p. 2053-8.

71. Liu, B., E.A. Garcia, and M. Korbonits, Genetic studies on the ghrelin, growth hormone secretagogue receptor (GHSR) and ghrelin O-acyl transferase (GOAT) genes. Peptides, 2011. 32(11): p. 2191-207.

72. Cabral, A., et al., Is Ghrelin Synthesized in the Central Nervous System? Int J Mol Sci, 2017. 18(3).

73. Sakata, I., et al., Glucose-mediated control of ghrelin release from primary cultures of gastric mucosal cells. Am J Physiol Endocrinol Metab, 2012. 302(10): p. E1300-10.

74. Callahan, H.S., et al., Postprandial suppression of plasma ghrelin level is proportional to ingested caloric load but does not predict intermeal interval in humans. J Clin Endocrinol Metab, 2004. 89(3): p. 1319-24.

75. le Roux, C.W., et al., Postprandial plasma ghrelin is suppressed proportional to meal calorie content in normal-weight but not obese subjects. J Clin Endocrinol Metab, 2005. 90(2): p. 106871.

76. Tannous dit El Khoury, D., et al., Variations in postprandial ghrelin status following ingestion of high-carbohydrate, high-fat, and high-protein meals in males. Ann Nutr Metab, 2006. 50(3): p. 260-9.

77. Monteleone, P., et al., Differential responses of circulating ghrelin to high-fat or highcarbohydrate meal in healthy women. J Clin Endocrinol Metab, 2003. 88(11): p. 5510-4.

78. Williams, D.L. and D.E. Cummings, Regulation of ghrelin in physiologic and pathophysiologic states. J Nutr, 2005. 135(5): p. 1320-5. 
79. Cummings, D.E., A.M. Naleid, and D.P. Figlewicz Lattemann, Ghrelin: a link between energy homeostasis and drug abuse? Addict Biol, 2007. 12(1): p. 1-5.

80. Cederbaum, A.l., Alcohol metabolism. Clin Liver Dis, 2012. 16(4): p. 667-85.

81. Gagnon, J. and Y. Anini, Insulin and norepinephrine regulate ghrelin secretion from a rat primary stomach cell culture. Endocrinology, 2012. 153(8): p. 3646-56.

82. Gagnon, J. and Y. Anini, Glucagon stimulates ghrelin secretion through the activation of MAPK and EPAC and potentiates the effect of norepinephrine. Endocrinology, 2013. 154(2): p. 666-74.

83. Godlewski, G., et al., Targeting Peripheral CB1 Receptors Reduces Ethanol Intake via a Gut-Brain Axis. Cell Metab, 2019. 29(6): p. 1320-1333 e8.

84. Iwakura, H., et al., Oxytocin and dopamine stimulate ghrelin secretion by the ghrelin-producing cell line, MGN3-1 in vitro. Endocrinology, 2011. 152(7): p. 2619-25.

85. Lu, X., et al., Postprandial inhibition of gastric ghrelin secretion by long-chain fatty acid through GPR120 in isolated gastric ghrelin cells and mice. Am J Physiol Gastrointest Liver Physiol, 2012. 303(3): p. G367-76.

86. Sakata, I., et al., The study of ghrelin secretion and acyl-modification using mice and ghrelinoma cell lines. Endocr J, 2017. 64(Suppl.): p. S27-S29.

87. Zhao, T.J., et al., Ghrelin secretion stimulated by \{beta\}1-adrenergic receptors in cultured ghrelinoma cells and in fasted mice. Proc Natl Acad Sci U S A, 2010. 107(36): p. 15868-73.

88. Bando, M., et al., High incorporation of long-chain fatty acids contributes to the efficient production of acylated ghrelin in ghrelin-producing cells. FEBS Lett, 2016. 590(7): p. 992-1001.

89. Watson, P.E., I.D. Watson, and R.D. Batt, Total body water volumes for adult males and females estimated from simple anthropometric measurements. Am J Clin Nutr, 1980. 33(1): p. 27-39.

90. Ramchandani, V.A., et al., A physiologically-based pharmacokinetic (PBPK) model for alcohol facilitates rapid BrAC clamping. Alcohol Clin Exp Res, 1999. 23(4): p. 617-23.

91. Zimmermann, U.S., S. O'Connor, and V.A. Ramchandani, Modeling alcohol self-administration in the human laboratory. Curr Top Behav Neurosci, 2013. 13: p. 315-53.

92. Sutherland, G.T., et al., The NSW brain tissue resource centre: Banking for alcohol and major neuropsychiatric disorders research. Alcohol, 2016. 52: p. 33-39.

93. Lee, M.R., et al., Effect of alcohol use disorder on oxytocin peptide and receptor mRNA expression in human brain: A post-mortem case-control study. Psychoneuroendocrinology, 2017. 85: p. 14-19.

94. Zallar, L.J., et al., Development and initial characterization of a novel ghrelin receptor CRISPR/Cas9 knockout wistar rat model. Int J Obes (Lond), 2019. 43(2): p. 344-354.

95. Darling, J.E., et al., A fluorescent peptide substrate facilitates investigation of ghrelin recognition and acylation by ghrelin O-acyltransferase. Anal Biochem, 2013. 437(1): p. 68-76.

96. Sieburg, M.A., E.R. Cleverdon, and J.L. Hougland, Biochemical Assays for Ghrelin Acylation and Inhibition of Ghrelin O-Acyltransferase. Methods Mol Biol, 2019. 2009: p. 227-241.

97. Darling, J.E., et al., Structure-activity analysis of human ghrelin O-acyltransferase reveals chemical determinants of ghrelin selectivity and acyl group recognition. Biochemistry, 2015. 54(4): p. 1100-10. 
Figure Titles and Legends:

Figure 1: Schematic Overview of Human Laboratory Alcohol Administration Experiments

Overview of human laboratory experiments depicting meals (blue), duration of alcohol intake (green), and blood draw times (black). Other study procedures not involving alcohol administration are also outlined (gray) 1A: Oral priming and alcohol self-administration experiment. Blood draw timepoints relative to $0=$ alcohol administration at 13:15 are T-280, T-15, T15, T165 min 1B: Fixed oral alcohol administration experiment. Blood draw timepoints relative to $0=$ alcohol administration at 10:15 are $\mathrm{T}$ 90, T0, T30, T90, T120, and T210 min 1C: Intravenous variable dose alcohol self-administration experiment. Blood draw timepoints relative to $0=$ alcohol administration at 12:00 are T-30, T30, T60, T90, and T120 min 1D: Fixed intravenous alcohol administration experiment. Blood draw timepoints relative to $0=$ alcohol administration at 13:00 are $\mathrm{T}-45, \mathrm{~T} 0, \mathrm{~T} 20, \mathrm{~T} 30$, and $\mathrm{T} 40 \mathrm{~min}$.

\section{Figure 2: Effect of Alcohol Administration on Peripheral Ghrelin Levels in Humans}

Plasma ghrelin levels over the course of different alcohol administration experiments in participants with heavy drinking. Gray zones indicate time periods of alcohol administration. For all data, 0 min = beginning of alcohol administration session. Data are presented as Mean \pm SEM. 2A: Oral variable-dose alcohol administration (Oral Priming and self-administration) analysis $(\mathrm{N}=16)$; fixed effect of time ($280,-15,15,165)$ on acyl-ghrelin (Left: $p<0.002)$ and total ghrelin (Right: $p=0.009$ ); pairwise comparisons: acyl-ghrelin (-280 vs. 165, -15 vs. 165; p < 0.05), total ghrelin (-280 vs. 165; p < 0.05). 2B: Oral fixed-dose alcohol administration analysis $(\mathrm{N}=12)$; fixed effect of time $(-90,0,30,90,120$, and 210 min) on acyl-ghrelin (Left: $\mathrm{p}<0.0001$ ) and total ghrelin (Right: $\mathrm{p}<0.0001$ ); pairwise comparisons: acylghrelin (0 vs. -90; $\mathrm{p}<0.05,0$ vs. 30, 90, 120, 210; $\mathrm{p}<0.001)$, total ghrelin (0 vs. $-90,30,210 ; \mathrm{p}<0.05,0$ vs. 120, $\mathrm{p}<0.001) 2 \mathrm{C}$ : IV variable-dose alcohol administration analysis $(\mathrm{N}=11)$; fixed effect of time (- 
30, 30, 60, 90, and $120 \mathrm{~min}$ ) on acyl-ghrelin (Left: $\mathrm{p}<0.0001$ ), and total ghrelin (Right: $\mathrm{p}<0.0001$ ); pairwise comparisons: acyl-ghrelin (-30 vs. 30; $\mathrm{p}<0.05,-30$ vs. 60, 90, 120; $\mathrm{p}<0.001)$, total ghrelin $(-30$ vs. 30, 60; $\mathrm{p}<0.05,-30$ vs. 120; $\mathrm{p}<0.01)$. 2D: IV fixed-dose alcohol administration analysis $(\mathrm{N}=6)$ evaluated a fixed effect of timepoint $(-45,0,20,30$, and $40 \mathrm{~min})$ on acyl-ghrelin (Left: $\mathrm{p}=N S)$, and total ghrelin (Right: $\mathrm{p}=N S$ ). $\mathrm{P}$ values presented for pairwise comparisons are Bonferroni corrected.

\section{Figure 3: Central Post Mortem Expression of GHSR, GHRL, and MBOAT4 in AUD Individuals and}

\section{Controls}

Fold expression of GHSR, GHRL, and MBOAT4 in 5 selected brain regions examined in post-mortem brain tissue from individuals with AUD and controls. Fold expression change is expressed as $2^{-\Delta \Delta C t}$ where $\Delta \Delta \mathrm{Ct}$ is the difference in $\Delta \mathrm{Ct}$ between $\mathrm{AUD}$ and control samples and $\Delta \mathrm{Ct}$ is difference in cycle threshold $(\mathrm{Ct})$ for the gene of interest - GADPH in the same sample. No regions are significantly different from each other after controlling for multiple comparisons. AMG = amygdala, AUD = alcohol use disorder, GHRL $=$ growth hormone receptor ligand (ghrelin gene), GHSR $=$ growth hormone secretagogue receptor (ghrelin receptor gene), HIPP $=$ hippocampus, MBOAT4 $=$ membrane bound o-acyl transferase 4 (GOAT gene), NA = nucleus accumbens, $\mathrm{PFC}=$ prefrontal cortex, VTA = ventral tegmental area.

\section{Figure 4: Effect of Ethanol on Peripheral Ghrelin Levels in Ghsr KO and WT Rats}

4A: Effect of ethanol (1.5 g/kg, i.p.) on plasma acyl-ghrelin levels in Ghsr KO and WT rats. Data represents change in ghrelin secretion with ethanol treatment $v s$. saline. $\mathrm{N}=8-9 /$ group. Treatment effect: $\mathrm{p}<0.019$, Genotype effect: $\mathrm{p}=N S$, and Interaction effect: $\mathrm{p}=N S .4 \mathrm{~B}$ : Effect of ethanol (1.5 g/kg, i.p.) on plasma des-acyl-ghrelin levels in Ghsr KO and WT Rats. Data represent change in ghrelin secretion with ethanol vs. saline treatment. $\mathrm{N}=8-9$ /group. Treatment effect: $\mathrm{p}=N S$, Genotype effect: $\mathrm{p}=N S$, and Interaction effect: $\mathrm{p}=$ NS. Data are presented as Mean \pm SEM. $\mathrm{p}<0.05$ considered significant. ${ }^{\mathrm{p}} \mathrm{p}<0.05$. 


\section{Figure 5: Effect of Ethanol on Ghrelin Secretion from Gastric Mucosal Cells}

5A: Effect of increasing concentrations of ethanol on acyl-ghrelin secretion in mouse primary gastric mucosal cells incubated with medium containing $5 \mathrm{mM}$ glucose. Data represent change in ghrelin secretion with ethanol $(\mathrm{EtoH})$ treatment compared to untreated control $(0 \mathrm{mM} \mathrm{EtoH}) . \mathrm{N}=4$ for each condition. $* * * * \mathrm{p}<0.0001$, one-way ANOVA followed by Dunnett's test. 5B: Effect of increasing concentrations of ethanol on acyl-ghrelin secretion in mouse primary gastric mucosal cells incubated with medium containing $0 \mathrm{mM}$ glucose. Data represents change in ghrelin secretion with EtoH treatment compared to untreated control $(0 \mathrm{mM}$ EtoH). $\mathrm{N}=4$ for each condition. $* * * \mathrm{p}<0.0001$, one-way ANOVA followed by Dunnett's test. 5C: Effect of increasing concentrations of ethanol on acyl-ghrelin secretion in mouse primary gastric mucosal cells incubated with medium containing either 5 or $0 \mathrm{mM}$ glucose (for reference only). Data represents change in ghrelin secretion with treatment compared to untreated control ( $0 \mathrm{mM}$ EtoH in $5 \mathrm{mM}$ glucose). $\mathrm{N}=4$ for each condition.

\section{Figure 6: Change in Peripheral Ghrelin as a Result of Alcohol or Sucrose}

6A: Plasma acyl-ghrelin and des-acyl-ghrelin resulting from alcohol and saline at baseline (BL) and 15 min and 60 min post-injection. Acyl-ghrelin (left): Two-way repeated measures (RM) ANOVA: overall treatment $(\mathrm{p}<0.05)$ and interaction $(\mathrm{p}<0.0001)$ effect. Post-hoc testing revealed a decrease in acylghrelin levels at $15 \mathrm{~min}(\mathrm{p}=0.003)$ and $60 \mathrm{~min}(\mathrm{p}=0.004)$ following ethanol treatment, compared with the pre-treatment baseline. When compared to saline injections, acyl-ghrelin levels were significantly lower in ethanol-treated rats at 60 min post-treatment $(\mathrm{p}=0.002)$. Des-acyl-ghrelin (right): Two-way RM ANOVA: overall time $(\mathrm{p}<0.05)$, treatment $(\mathrm{p}<0.05)$, and interaction $(\mathrm{p}<0.05)$. Post-hoc testing revealed significant increases in des-acyl-ghrelin at $15 \min (\mathrm{p}=0.047)$ and $60 \mathrm{~min}(\mathrm{p}=0.018)$ following saline treatment, whereas no changes in des-acyl-ghrelin levels were observed following ethanol 
treatment. Des-acyl-ghrelin levels following saline treatment were significantly higher compared to ethanol treatment at $60 \mathrm{~min}(\mathrm{p}=0.038) .6 \mathrm{~B}$ : Plasma acyl-ghrelin and des-acyl-ghrelin resulting from sucrose and saline treatment at baseline and 15 and 60 min post-inejction. Acyl-ghrelin (left): Two-way RM ANOVA: overall treatment $(\mathrm{p}<0.05)$ effect. Post-hoc testing revealed significantly lower acylghrelin levels at $60 \mathrm{~min}$ following sucrose treatment, compared to saline treatment $(\mathrm{p}=0.002)$. Des-acylghrelin (right): Two-way ANOVA: overall time $(\mathrm{p}<0.0001)$ effect. Post-hoc testing revealed a significant increase in des-acyl-ghrelin at $15 \min (\mathrm{p}=0.031)$ and $60 \mathrm{~min}(\mathrm{p}<0.001)$, compared to baseline, and at $60 \min (\mathrm{p}=0.0190)$, compared to 15 min. Post-hoc Sidak's multiple comparison tests: *p $<0.05, * * \mathrm{p}<0.01, * * * \mathrm{p}<0.001, * * * * \mathrm{p}<0.0001$ 
bioRxiv preprint doi: https://doi.org/10.1101/2020.07.30.228494; this version posted July 31, 2020. The copyright holder for this preprint (which

was not certified by peer review) is the author/funder. This article is a US Government work. It is not subject to copyright under 17 USC 105 and is also made available for use under a CCO license.

Tables:

Table 1: Comparison of GHRL, GHSR, and MBOAT4 expression changes in Post-mortem Brain Tissue between AUD and Controls

\begin{tabular}{|c|c|c|c|c|c|c|}
\hline & $\begin{array}{l}\text { AUD } \\
{ }^{\mathrm{a}} \Delta \mathrm{Ct}\end{array}$ & $\begin{array}{l}\text { Control } \\
{ }^{\mathrm{a}} \Delta \mathrm{Ct}^{\mathrm{a}}\end{array}$ & $\begin{array}{c}\text { AUD } \\
\mathbf{b}^{-\Delta \Delta C t}\end{array}$ & $\begin{array}{l}\text { Control } \\
{ }^{b} 2^{-\Delta A C t}\end{array}$ & Statistic & Adjusted p-value \\
\hline \multicolumn{7}{|l|}{ GHRL } \\
\hline HIPP & 12.5 & 12.3 & 0.80 & 1.02 & $\begin{array}{c}\mathrm{F}(1,17)=5.311, \mathrm{p}=0.034 \\
{ }^{\mathrm{c} B r a i n} \mathrm{pH}, \mathrm{PMI}, \text { Age }\end{array}$ & $\mathrm{P}=0.17$ \\
\hline AMY & 10.3 & 10.2 & 0.85 & 0.93 & $\mathrm{~F}(1,19)=0.846, \mathrm{p}=0.369$ & $\mathrm{P}=1$ \\
\hline PFC & 12.9 & 13.0 & 1.04 & 0.98 & $F(1,20)=0.354, p=0.559$ & $\mathrm{P}=1$ \\
\hline NA & 11.3 & 11.4 & 0.93 & 0.90 & $\mathrm{~F}(1,18)=0.218, \mathrm{p}=0.646$ & $\mathrm{P}=1$ \\
\hline VTA & 11.5 & 11.4 & 0.96 & 1.00 & $\begin{array}{c}\mathrm{F}(1,19)=3.900, \mathrm{p}=0.063 \\
{ }^{\mathrm{c}} \text { Pack years }\end{array}$ & $P=0.315$ \\
\hline \multicolumn{7}{|l|}{ GHSR } \\
\hline HIPP & 10.1 & 9.1 & 0.90 & 1.35 & $\mathrm{~F}(1,21)=1.206, \mathrm{p}=0.284$ & $\mathrm{P}=1$ \\
\hline AMY & 12.6 & 13.1 & 1.77 & 1.67 & $\mathrm{~F}(1,20)=0.098, \mathrm{p}=0.758$ & $\mathrm{P}=1$ \\
\hline PFC & 14.4 & 15.5 & 2.95 & 1.24 & $\mathrm{~F}(1,18)=4.195, \mathrm{p}=0.055$ & $\mathrm{P}=0.275$ \\
\hline NA & 10.4 & 9.9 & 1.49 & 1.25 & $\begin{array}{c}\mathrm{F}(1,18)=1.126, \mathrm{p}=0.303 \\
{ }^{\mathrm{c}} \text { Brain } \mathrm{pH}, \mathrm{PMI}\end{array}$ & $P=1$ \\
\hline VTA & 12.9 & 13.1 & 1.18 & 0.91 & $\mathrm{~F}(1,20)=1.829, \mathrm{p}=0.191$ & $\mathrm{P}=0.96$ \\
\hline \multicolumn{7}{|c|}{ MBOAT4 } \\
\hline HIPP & 14.3 & 14.8 & 0.91 & 1.19 & $\mathrm{~F}(1,19)=3.036, \mathrm{p}=0.098$ & $\mathrm{P}=0.49$ \\
\hline AMY & 11.7 & 11.5 & 1.17 & 1.03 & $\mathrm{~F}(1,22)=1.731, \mathrm{p}=0.202$ & $\mathrm{P}=1$ \\
\hline PFC & 13.0 & 13.4 & 1.28 & 0.94 & $\mathrm{~F}(1,19)=3.564, \mathrm{p}=0.074$ & $\mathrm{P}=0.37$ \\
\hline NA & 12 & 11.6 & 0.84 & 0.97 & $\begin{array}{c}\mathrm{F}(1,15)=4.693, \mathrm{p}=0.047 \\
{ }^{\mathrm{c}} \text { Packyears, BMI }\end{array}$ & $P=0.235$ \\
\hline VTA & 15.2 & 15.3 & 0.88 & 0.94 & $\begin{array}{c}\mathrm{F}(1,14)=3.502, \mathrm{p}=0.082 \\
{ }^{\mathrm{c}} \text { Pack years }\end{array}$ & $P=0.41$ \\
\hline
\end{tabular}


GHSR = growth hormone secretagogue receptor, GHRL = growth hormone receptor ligand, MBOAT4 = membrane bound o-acyl-transferase 4, AUD $=$ alcohol use disorder, HIPP $=$ hippocampus, $\mathrm{AMY}=$ amygdala, PFC $=$ pre-frontal cortex, NAc $=$ nucleus accumbens, VTA $=$ ventral tegmental area, $\mathrm{PMI}=$ post-mortem interval

${ }^{\mathrm{a}} \Delta \mathrm{Ct}=$ Cycle threshold $(\mathrm{Ct})$ of gene of interest (MBOAT4, GHSR, or GHRL) - cycle threshold for GADPH (housekeeping gene used as endogenous control)

${ }^{\mathrm{b}} 2^{-\Delta \Delta \mathrm{Ct}}$ calculated based on $\Delta \Delta \mathrm{Ct}=\Delta \mathrm{Ct}$ AUD $-\Delta \mathrm{Ct}$ Controls

${ }^{\mathrm{c}}$ Covariates in final model 


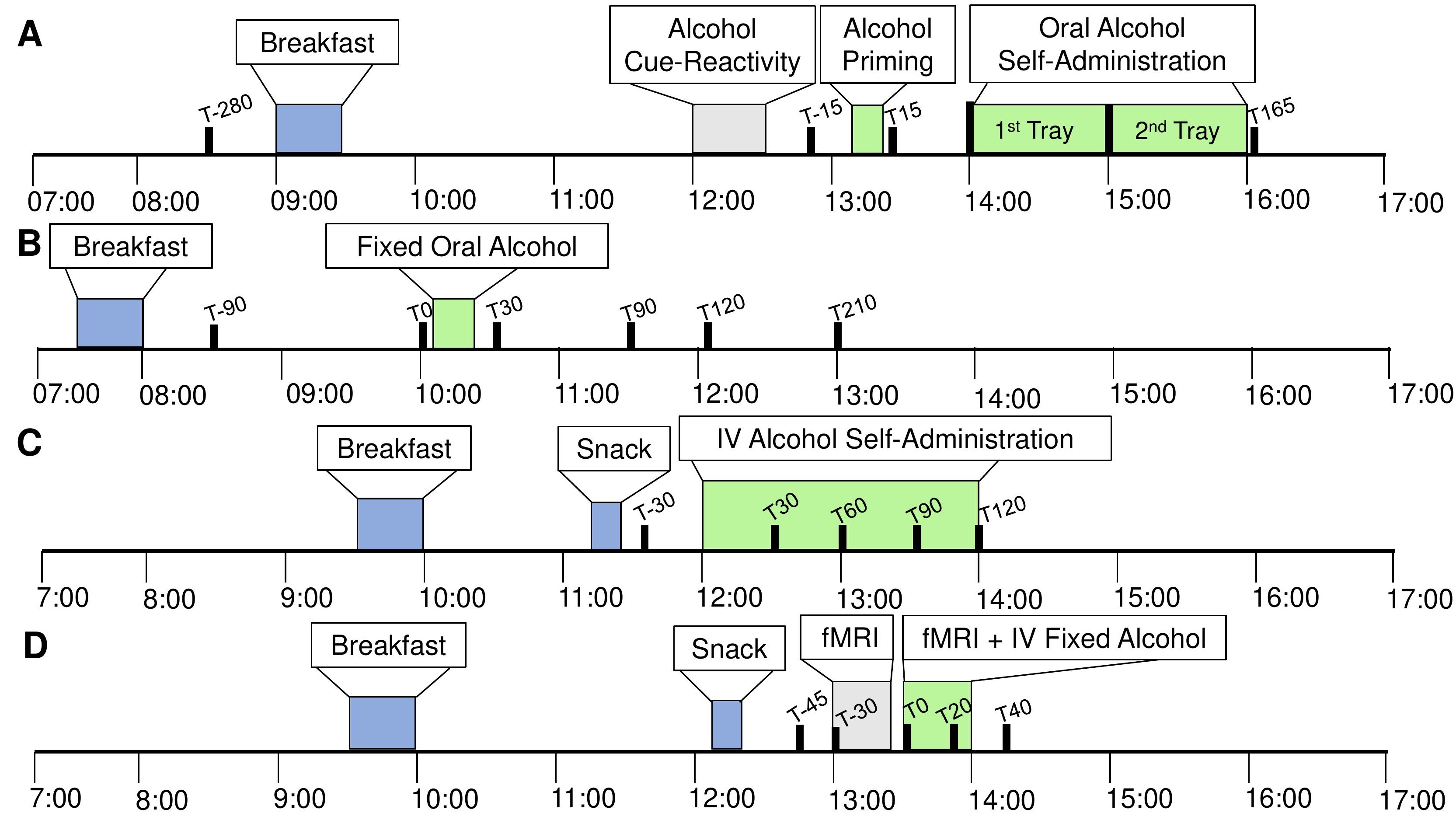


A bioRxiv presing doi: https://doi.org/10.1101/2020.07.30.228494; this version clefsted July 31, 2020. The copyright $h$ a was not certified by peer review) is the author/funder. This article is a US Government work. It is not subject to co
and is also made available for use under a CCO license.

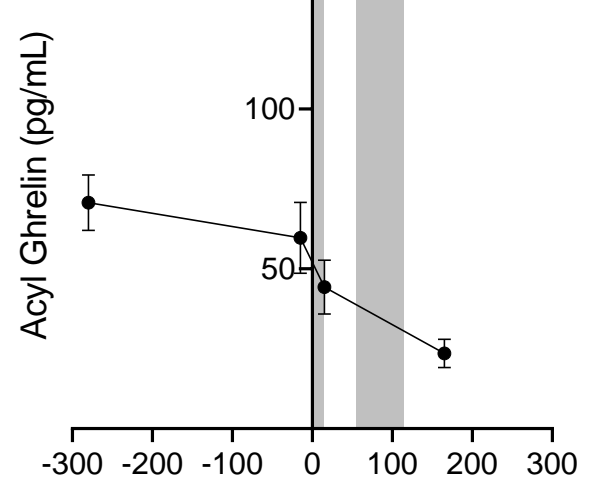

Time (min)
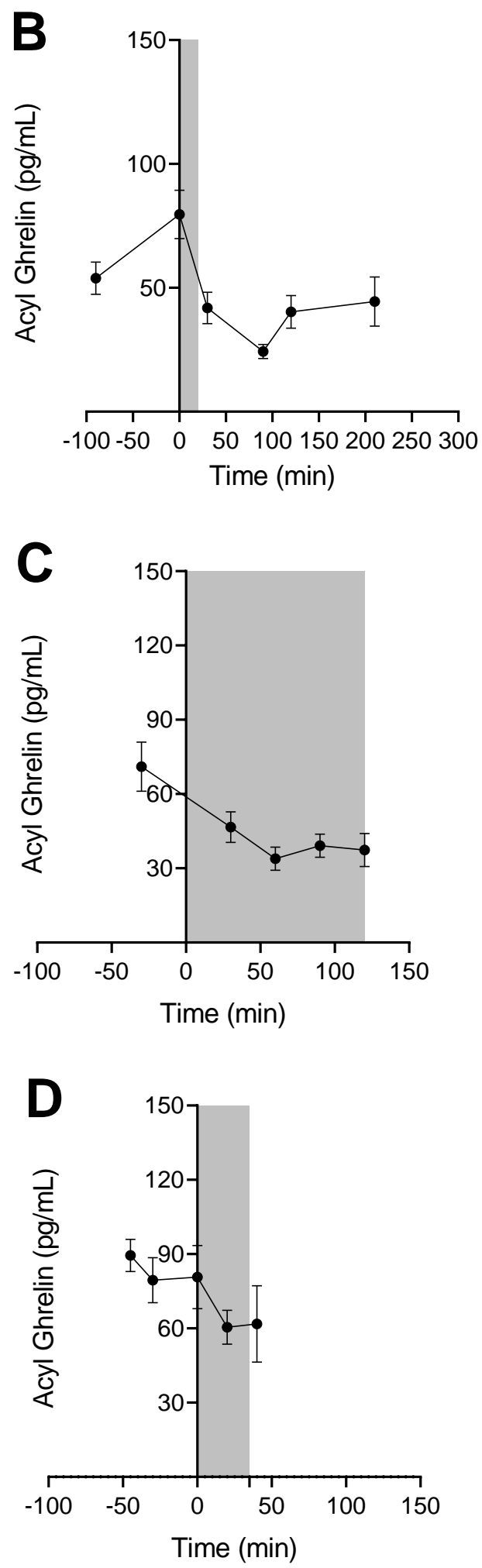
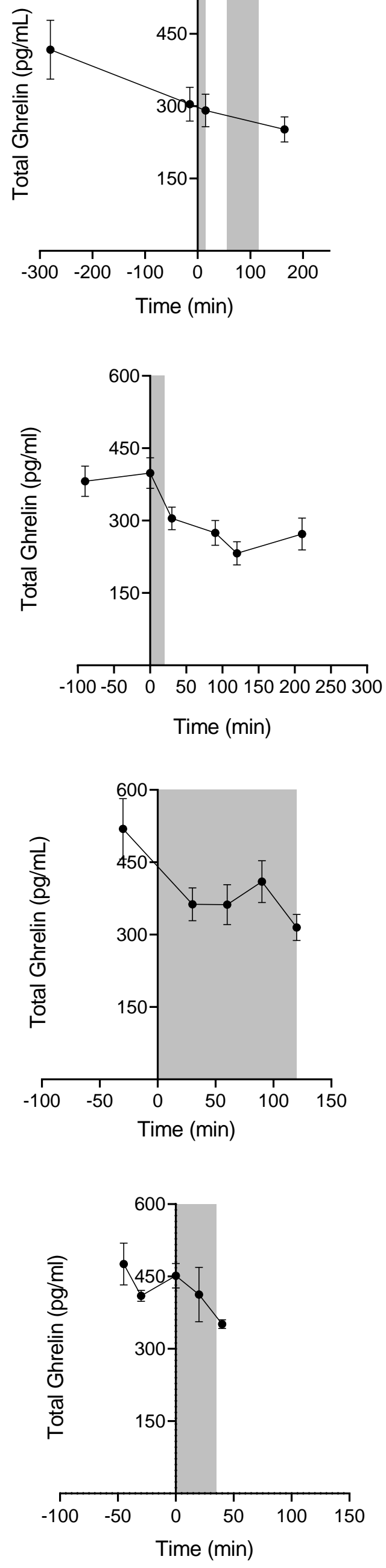
GHSRP was not certified by peer review) is the author/funder. This article is a US Government work. It is not subject to copyright under 17 USC

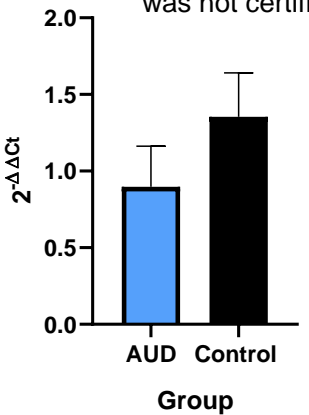

GHSR-AMG

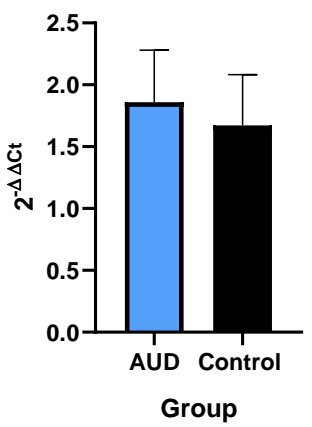

GHSR-PFC

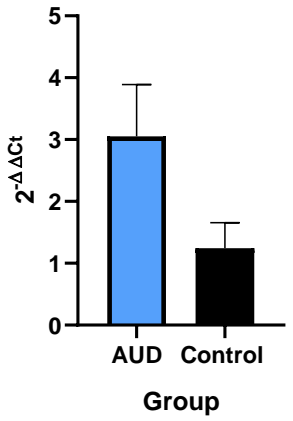

GHSR-VTA

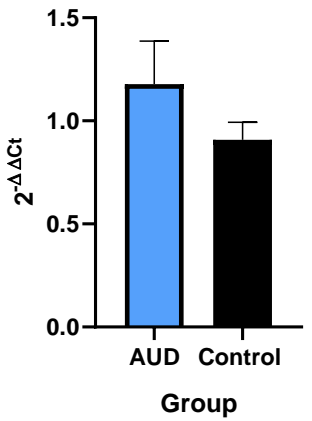

GHSR-VTA

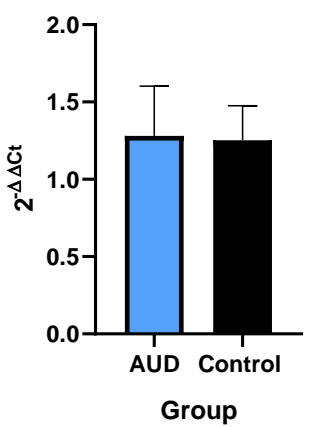

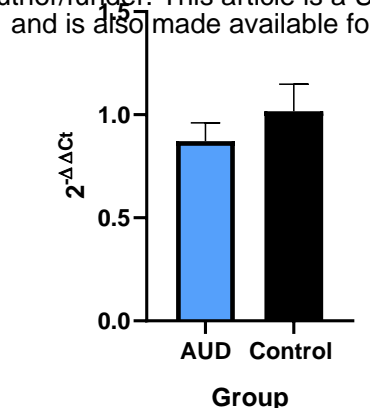

GHRL- AMG

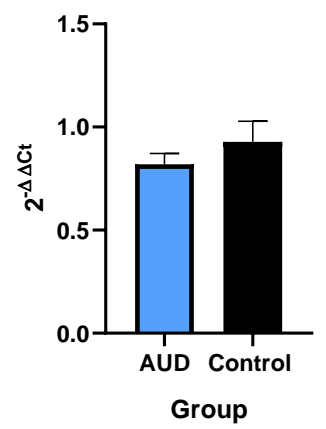

GHRL- PFC

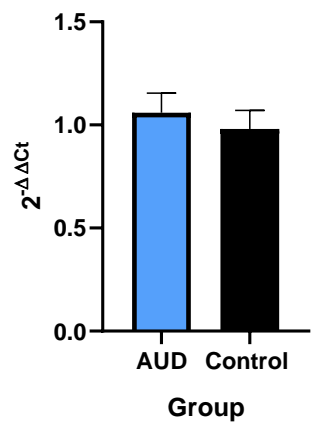

GHRL- VTA

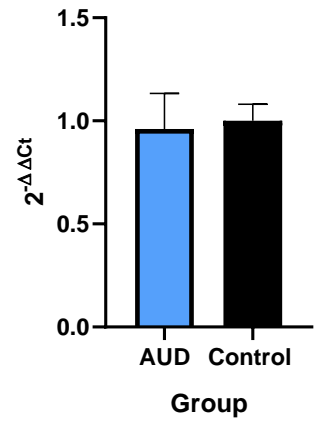

GHRL- NA

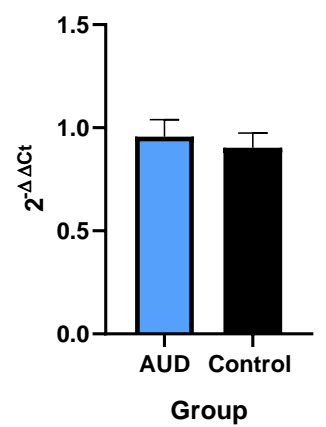

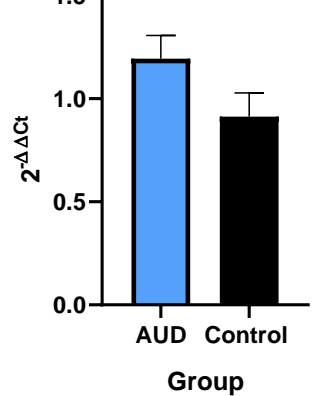

MBOAT4-AMG

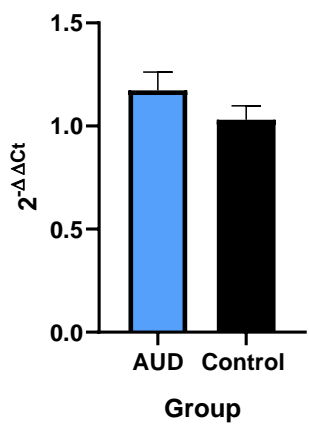

MBOAT4-PFC

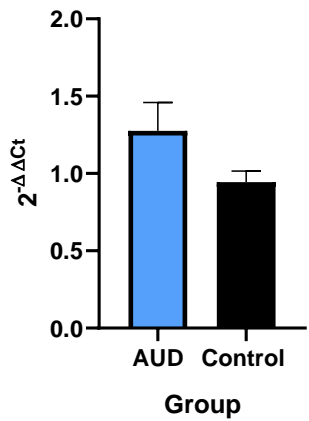

MBOAT4-VTA

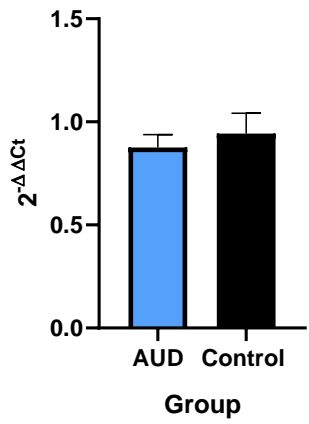

MBOAT4-NA

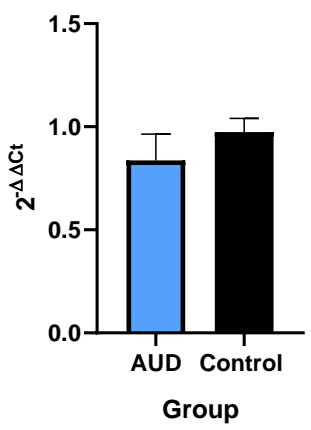


A

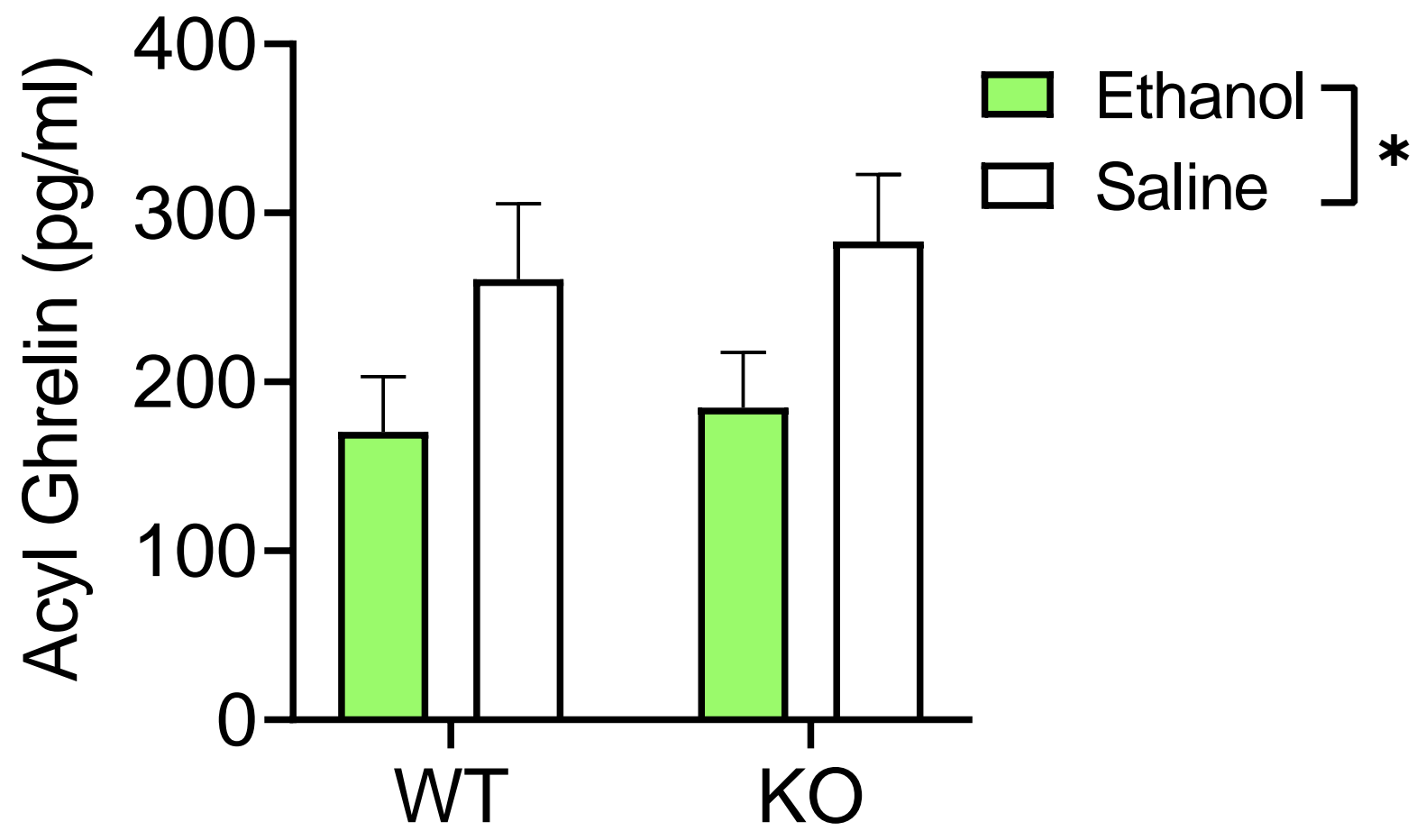

B

Group

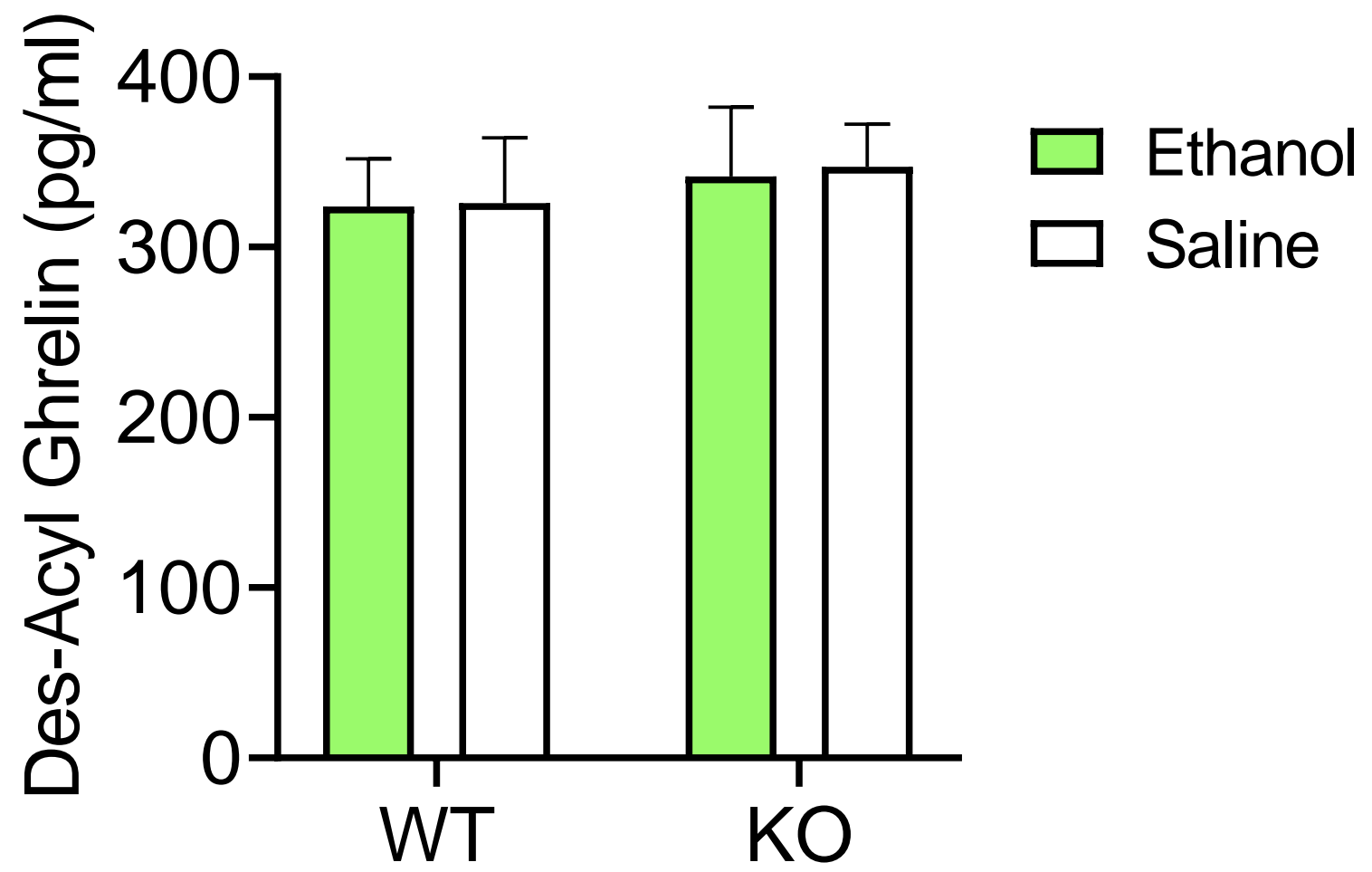

Group 
A.

\section{$5 \mathrm{mM}$ Glucose}

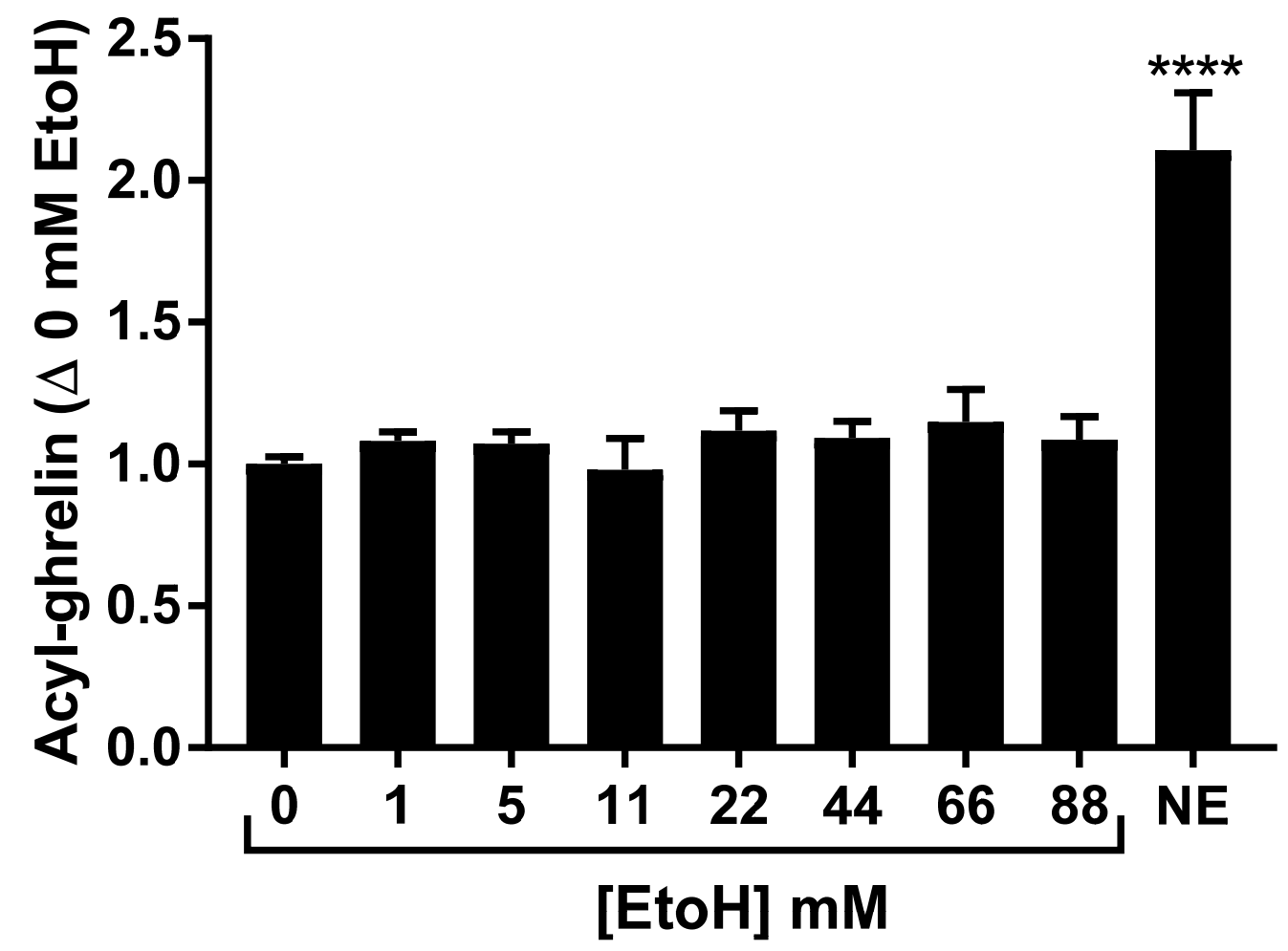

B.

$0 \mathrm{mM}$ Glucose

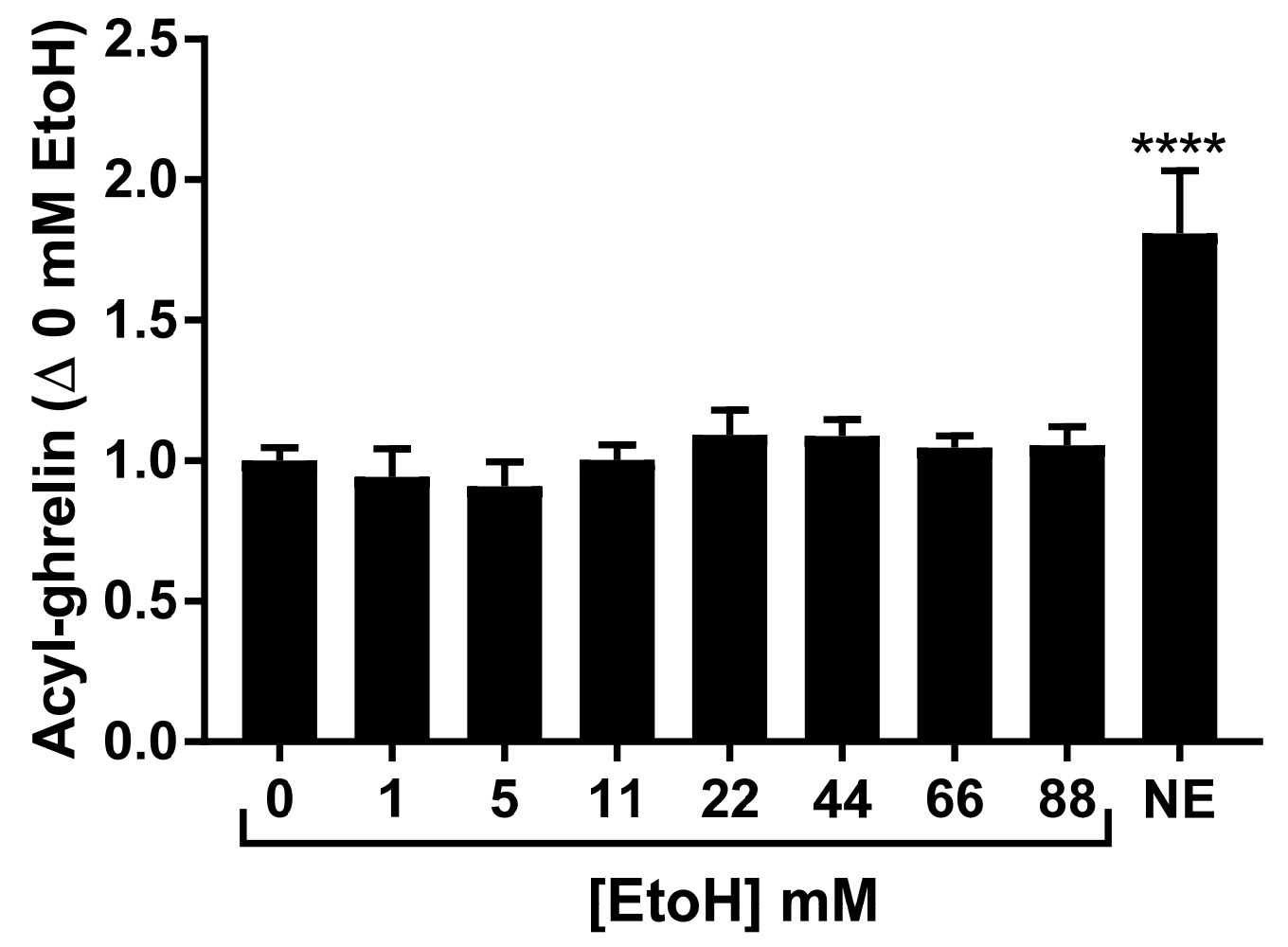


C.

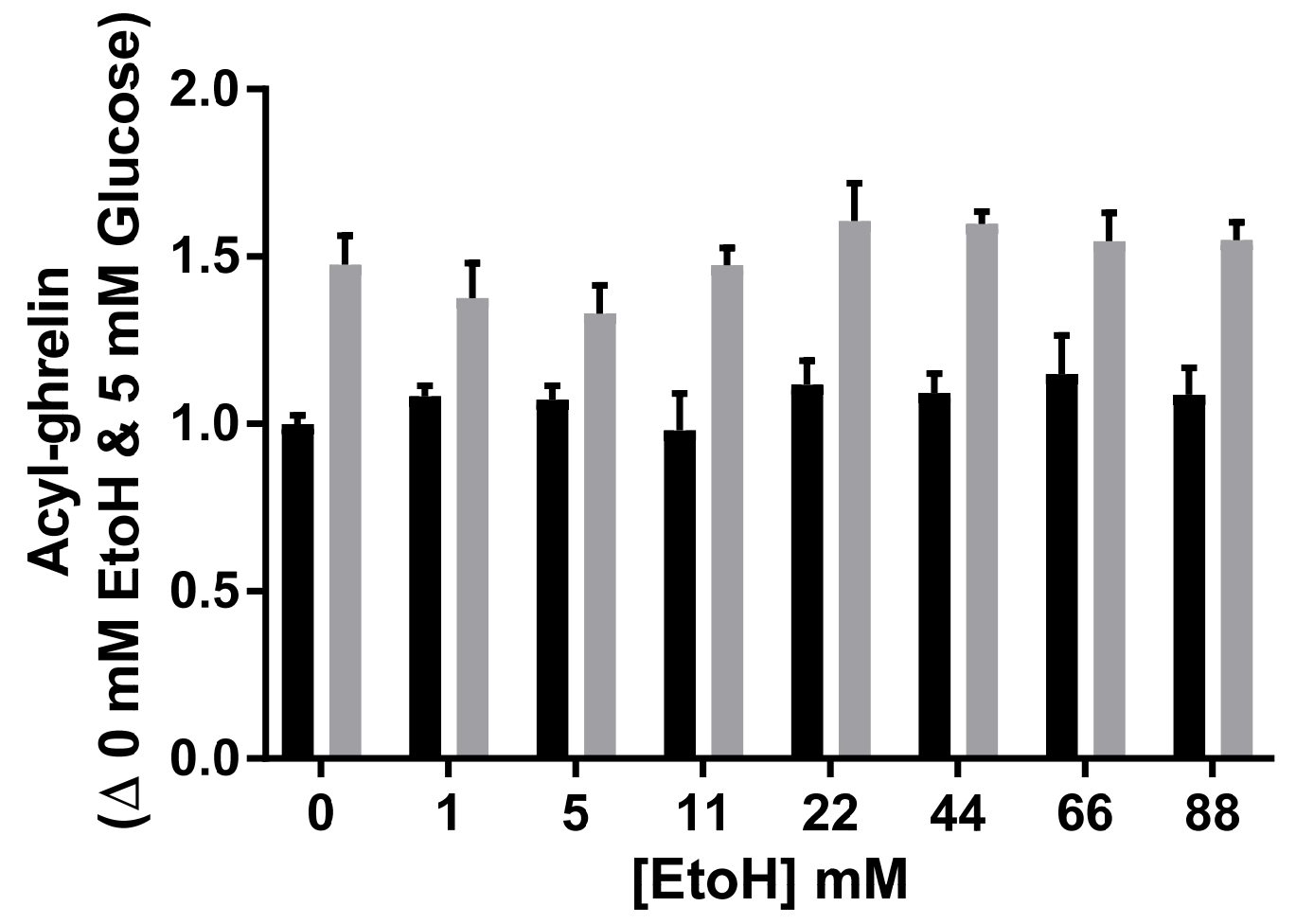

$5 \mathrm{mM}$ Glucose $\quad 0 \mathrm{mM}$ Glucose 
A
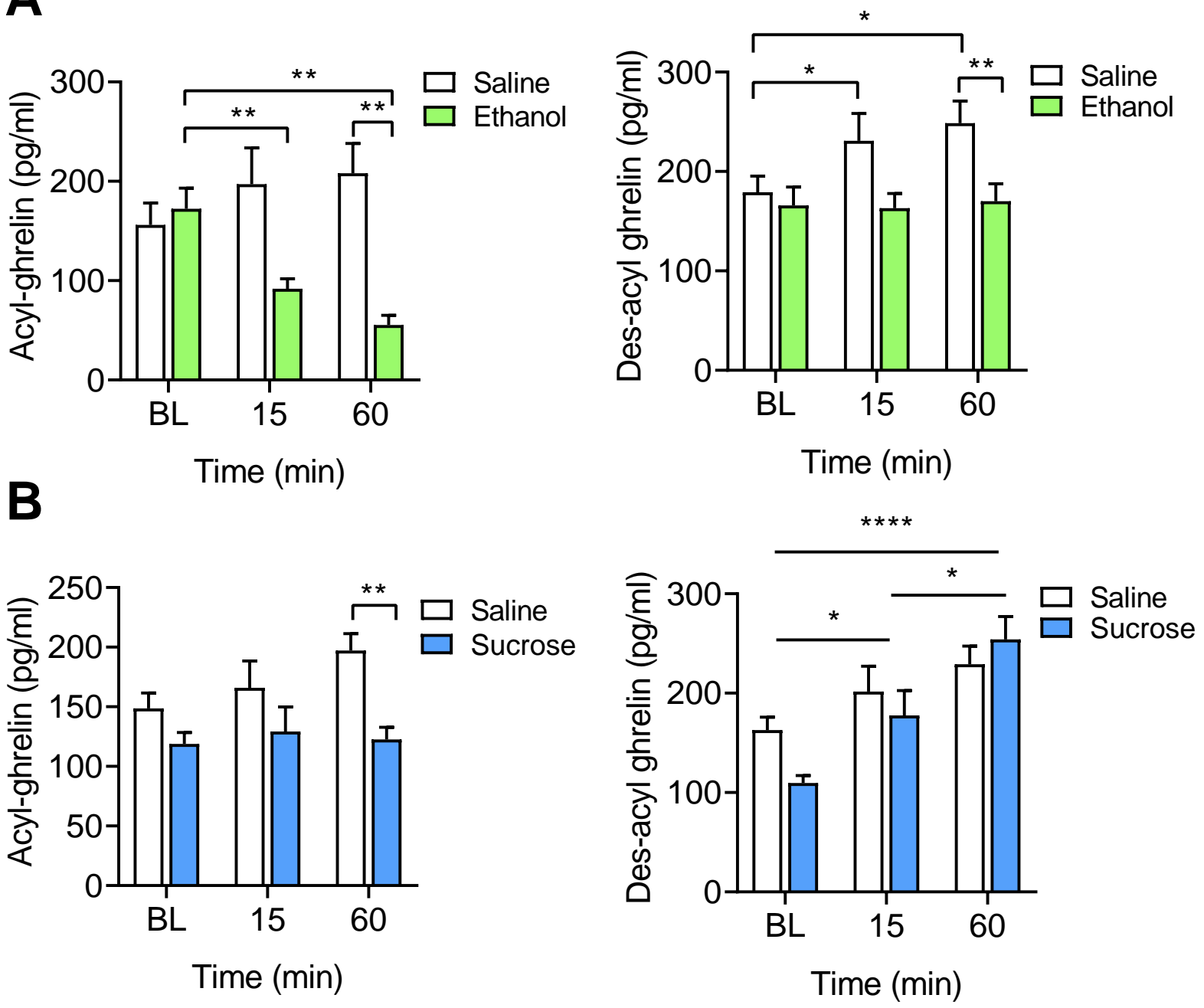